MARQUÈS I BANQUÉ, Maria. "Problemas de legitimación del Derecho penal del miedo".

Polít. crim. Vol. 12, No 24 (Diciembre 2017), Art. 2, pp. 690-730.

[http://www.politicacriminal.cl/Vol_12/n_24/Vol12N24A2.pdf]

\title{
Problemas de legitimación del Derecho penal del miedo
}

\section{Legitimacy problems of fear-based Criminal law}

\author{
Maria Marquès i Banqué \\ Profesora Colaboradora Permanente de Derecho Penal \\ Universitat Rovira i Virgili \\ maria.marques@urv.cat
}

\section{Resumen}

En un contexto como el actual es preciso volver al discurso de la legitimación del Derecho penal y revisitar el marco conceptual que debería servir de base para la evaluación crítica de las políticas legislativas penales de un Estado social y democrático de Derecho. Con este fin, en el presente trabajo se apuntan algunos problemas de legitimación que plantea el "Derecho penal del miedo", término que pretende describir la cada vez más consolidada tendencia a orientar la intervención punitiva a la consecución de la sensación de seguridad (seguridad subjetiva), y que afecta hoy en día a ámbitos de criminalidad de muy distinta naturaleza. Desde postulados garantistas, se sostiene que la orientación a la seguridad subjetiva que caracteriza el Derecho penal del miedo y la instrumentalización política que se deriva de la misma, suponen una funcionalización ilegítima, en la medida que abre la puerta a la perversión de las funciones y fines del Derecho penal con la vulneración, en ocasiones encubierta, del principio de protección de bienes jurídicos. La prevalencia de las funciones latentes por encima de la protección de bienes jurídicos en la promulgación de una norma penal constituye una de las posibles causas de su potencial ineficacia instrumental. En la medida en que así sea, podrá afirmarse que dicha norma tiene únicamente efectos simbólicos.

Palabras clave: Derecho penal del miedo, seguridad subjetiva, instrumentalización política, funcionalización ilegítima, Derecho penal simbólico.

\begin{abstract}
In the current social and political scenario, it is necessary to return to the discourse of the legitimation of Criminal law and revisit the conceptual framework that should serve as a basis for the critical assessment of the criminal policies of a social and democratic State ruled by law. This paper aims to point out some of the problems of legitimacy posed by the "Fear-based Criminal law", a term that seeks to describe the increasingly consolidated tendency to use Criminal law for providing a sense of safety, which today affects areas of criminality of very different nature. It is argued that addressing the sense of safety by means of Criminal law is a kind of political manipulation. It also means an illegitimate functionalization, as it opens the door to the perversion of functions of Criminal law. The prevalence of latent functions over the protection of values in Criminal law is one of the
\end{abstract}


MARQUÈS I BANQUÉ, Maria. "Problemas de legitimación del Derecho penal del miedo".

possible causes of its potential instrumental inefficacy. When this occurs, it can be said that such a norm has only symbolic effects.

Key words: Fear-based Criminal law, sense of safety, political manipulation, illegitimate functionalization, symbolic Criminal law.

\section{Introducción}

La idea de seguridad preside hoy el debate político-criminal. Esta afirmación parece difícilmente discutible a la vista de las iniciativas legislativas penales llevadas a cabo durante las dos últimas décadas en distintos países occidentales, así como de las observaciones que la doctrina ha hecho a las mismas, ya sea en sentido crítico o para dotarlas de una cobertura teórica que les sirva de justificación. En el caso de España, no es extraño leer expresiones como "ideología de la seguridad", "políticas securitarias", o "expansión securitaria" cuando se abordan las reformas penales, procesales y penitenciarias de naturaleza abiertamente represiva y punitivista que han tenido lugar desde $2003^{1}$.

La doctrina ha puesto de relieve cómo esta deriva punitivista de las políticas criminales que se está viendo en sociedades modernas y democráticas -incluso en aquellas con gobiernos progresistas- ha desconcertado a todos los que estaban "convencidos de que la evolución del Derecho penal, desde los finales de la II Guerra Mundial, había tomado un rumbo hacia la racionalidad y hacia su definitiva humanización. De modo que, aún con gobiernos conservadores, se daba por descontado, que determinados límites de racionalidad ya no se iban a traspasar"2. La toma de conciencia sobre la generalización del discurso político en torno a la seguridad es importante porque evita la tentación de hacer una aproximación demasiado simplista a las reformas penales, en el sentido de atribuir la expansión del Derecho penal exclusivamente a "la intolerancia política de un determinado grupo político"3. Así, por ejemplo, en materia de seguridad ciudadana en España, se observó

\footnotetext{
${ }^{1}$ Sin ánimo de exhaustividad, son cuestiones abordadas por las reformas penales en España desde 2003: la reintroducción de las penas cortas privativas de libertad; la ampliación del máximo de cumplimiento efectivo de la condena; la reforma del tercer grado penitenciario con la introducción del llamado "período de seguridad"; el endurecimiento del régimen de cumplimiento aplicable en supuestos de acumulación de condenas; la reintroducción de la agravante de multireincidencia; la sustancial reforma del régimen de suspensión de la ejecución de la pena y, como consecuencia, el endurecimiento del régimen de libertad condicional, la ampliación de la posibilidad de sustitución de la pena por la expulsión del territorio nacional en caso de extranjeros no residentes legalmente en España; la introducción de la libertad vigilada como medida de seguridad; la introducción de la pena de prisión permanente revisable.

2 DEL ROSAL BLASCO, B., "La estrategia actuarial de control del riesgo en la política criminal y en el Derecho Penal", en: CARBONELL MATEU, J.C.; GONZÁLEZ CUSSAC, J.L.; ORTS BERENGUER, E. (Dirs.), Constitución, Derechos Fundamentales y Sistema Penal, Tomo I, Valencia: Tirant lo Blanch, 2009 , p. 474.

${ }^{3}$ DE LA MATA BARRANCO, N. J., "Las reformas penales de 2003: consideraciones generales sobre la quiebra de algunos principios que deben definir toda intervención penal", en: FARALDO CABANA, P. (Dir.), Política Criminal y reformas penales, Valencia: Tirant lo Blanch, 2007, pp. 12-13. Llaman también la atención sobre el consenso político en torno al recurso al Derecho penal de nuevo como 'prima ratio', por ejemplo, CANCIO MELIÁ, M., "Dogmática y Política Criminal en una teoría funcional del delito", en: JAKOBS, G.; CANCIO MELIÁ, M., Conferencias sobre temas penales, Buenos Aires: Rubinzal-Culzoni Editores, 2004 (reimpresión), pp. 135 y 136; CARBONELL MATEU, J.C.; GUARDIOLA GARCÍA, J., "Consideraciones sobre la reforma penal de 2003", Revista Jurídica de la Comunidad Valenciana 2004 (12),
} 
durante un tiempo cómo a pesar de las diferencias que podían existir en los programas políticos de los partidos políticos de derechas y de izquierdas, en todos se daba una misma tendencia inflacionista y represiva, siendo en opinión de los analistas "extremadamente similares" las líneas generales de sus propuestas ${ }^{4}$.

Las causas sociopolíticas y económicas de este fenómeno son sobradamente conocidas, pues mucho tienen que ver con la crisis del Estado del Bienestar, el auge del neoliberalismo y el impacto de sus políticas en la justicia penal, proceso que empezó a observarse ya en los años setenta del siglo pasado en Estados Unidos y que, a pesar de alguna observación optimista en cuanto al papel que en el freno de tal influjo podían jugar los penalistas europeos $^{5}$, terminó por llegar a Europa, aunque como es lógico, con matices y particularidades estudiadas tanto por criminólogos como penalistas ${ }^{6}$.

En el actual escenario global, el discurso político en torno a la seguridad propicia un muy amplio consenso social en torno a medidas que en otra época se habrían cuestionado con énfasis por, como mínimo, autoritarias y poco respetuosas con los derechos y las libertades individuales. A nadie escapa que en esta situación de consenso político en torno al valor prioritario y autónomo de la seguridad, el impacto que en materia de justicia penal puede tener la actual deriva política ultraconservadora de los países occidentales merece particular atención. .

p. 11; LANDROVE DÍAZ, G., "El Derecho penal 'de la seguridad", La Ley, t.4 (2003), p. 1925 (ref. D224); MAQUEDA ABREU, M., "Crítica a la reforma penal anunciada", Jueces para la Democracia núm. 47 (julio 2003), p. 6; SILVA SÁNCHEZ, J.M., La expansión del Derecho Penal. Aspectos de la política criminal en las sociedades postindustriales, Madrid: Civitas, 1999, p. 23; MUÑOZ CONDE, F., "El nuevo Derecho penal autoritario", en: OCTAVIO DE TOLEDO Y UBIETO, E.; GURDIEL SIERRA, M.; CORTÉS BECHIARELLI, E. (Coords.), Estudios Penales en recuerdo del profesor Ruiz Antón, Valencia: Tirant lo Blanch, 2004, p. 821. A modo de síntesis, puede verse un breve examen de la evolución en España del signo represivo de las reformas desde 1995 a 2009, en: LANDROVE DÍAZ, G., "Una cierta política criminal", en: CARBONELL MATEU, J.C.; GONZÁLEZ CUSSAC, J.L.; ORTS BERENGUER, E. (Dirs.), Constitución, Derechos Fundamentales y Sistema Penal, Tomo II, Valencia: Tirant lo Blanch, 2009, pp. 1079-1088. En cuanto a las importantes reformas de 2010 y 2015, véase QUINTERO OLIVARES, G. (Dir.), La reforma penal de 2010. Análisis y comentarios, Cizur Menor: Thomson Reuters Aranzadi, 2010 y QUINTERO OLIVARES, G. (Dir.), Comentario a la reforma penal de 2015, Cizur Menor: Thomson Reuters Aranzadi, 2015.

${ }^{4}$ Con detalle, MEDINA ARIZA, J., "Discursos políticos sobre seguridad ciudadana en la historia reciente de España", en: PÉREZ ÁLVAREZ, F. (Ed.), Serta in Memoriam Alexandri Baratta, Salamanca: Universidad de Salamanca, 2004, pp. 1305-1308.

${ }^{5}$ En este sentido, KUHLEN, L., "El Derecho penal del futuro" (trad. de A. Nieto Martín), en: ARROYO ZAPATERO, L.; NEUMANN, U.; NIETO MARTÍN, A. (Coords.), Crítica y Justificación del Derecho Penal en el cambio de siglo, Cuenca: Ediciones de la Universidad de Castilla-La Mancha, 2003, p. 227: "La sostenida tendencia consistente en acentuar los aspectos represivos del Derecho penal a través de la imposición de penas de muerte, utilización excesiva de penas privativas de libertad y sanciones estigmatizadoras tienen, a mi juicio, escasas posibilidades de influencia en el centro y oeste de Europa".

${ }^{6}$ Por su carácter monográfico, cabe destacar: BRANDARIZ GARCÍA, J.A., Política criminal de la exclusión, Granada: Comares, 2007, quien incluye un amplio análisis de la bibliografía relativa al fenómeno en Estados Unidos; PÉREZ CEPEDA, A.I., La seguridad como fundamento de la deriva del Derecho penal postmoderno, Madrid: Iustel, 2007; y PORTILLA CONTRERAS, G., El Derecho penal entre el cosmopolitismo universalista y el relativismo posmodernista, Valencia: Tirant lo Blanch, 2007. En inglés, véase un interesante análisis en BELL, E., Criminal Justice and Neoliberalism, Londres: Palgrave Macmillan UK, 2011. 
MARQUÈS I BANQUÉ, Maria. "Problemas de legitimación del Derecho penal del miedo".

En este contexto, parece casi obligado volver a uno de los problemas fundamentales del Derecho penal, cual es el discurso sobre su legitimación, y hacerlo recuperando los argumentos y autores que, desde postulados garantistas, alertaron hace tres décadas de los riesgos de contención del Derecho penal en la sociedad del riesgo. Entiendo por legitimación aquel proceso axiológico que, más allá de la mera comprobación del ajuste de las normas penales al procedimiento legalmente establecido para la promulgación de las leyes, hace referencia "a la fundamentación o justificación última del orden jurídico, así como a las condiciones y procesos de transmisión del poder legítimo"7. En la medida que no escapa a nadie que "sólo un genio o un charlatán podría atreverse a presentar en unas pocas páginas una teoría sobre el 'Derecho penal justo",", me limitaré a reflexionar en torno a la idea del miedo colectivo como criterio de legitimación del Derecho penal y a recordar algunos de los problemas que esta opción plantea en términos de instrumentalización política, funcionalización ilegítima y Derecho penal simbólico.

Desde el punto de vista terminológico, me referiré al "Derecho penal del miedo" para describir la orientación del Derecho penal a la seguridad subjetiva, entendida como percepción de ausencia de riesgo (en definitiva, la quimera de la eliminación del miedo).

Desde que empezara a hablarse de la "sociedad del riesgo" y del "Derecho penal del riesgo" hace ya tres décadas, el debate en torno al alcance de la idea de seguridad y la prevención en el Derecho penal ha evolucionado en muchas direcciones y con muy distintas consecuencias 9 . A la noción de seguridad vinculada a la masificación de los riesgos técnicos sobre el que partía la concepción de "sociedad del riesgo" y que comprendía, por citar algunos, los derivados de la energía atómica, la informática, la tecnología genética o los procesos químicos y biológicos con trascendencia sobre el medio ambiente o la cadena alimentaria, se sumaron muy pronto otros riesgos de muy distinta

\footnotetext{
7 JONGITUD ZAMORA, J., "Legalidad, legitimidad y legitimación. Implicaciones éticas”, en: CÁCERES, E., Problemas contemporáneos de la Filosofía del Derecho, México: Universidad Nacional Autónoma de México, 2005, p. 359.

8 ARZT, G., "Probleme der Kriminalisierung und Entkriminalisierung sozialschädlichen Verhaltens", Kriminalistik 1981, p. 117.

${ }^{9}$ De obligada cita es la obra de BECK, U., La sociedad del riesgo. Hacia una nueva modernidad, Barcelona: Paidós, 1998. A los efectos de este trabajo, es importante matizar que la noción de "sociedad del riesgo" no se agota en la formulación inicial de BECK. En este sentido, a partir del análisis de los modelos de "sociedad del riesgo" descritos por BECK, NOVOTNY/EVERS y KAUFMANN, ya PRITTWITZ señaló tres aspectos definitorios de la "sociedad del riesgo": en primer lugar, la necesaria aparición con el progreso técnico de grandes y nuevos procesos de riesgo cuyo control escapa a la capacidad singular del individuo a diferencia de lo que ocurría con los riesgos clásicos, extremo que se identificaría con el modelo definido por Beck; en segundo lugar, las nuevas formas de conocimiento y percepción del riesgo por parte de los miembros de la sociedad; y en tercer lugar, la inseguridad generada con carácter general como consecuencia de ello (PRITTWITZ, C., Strafrecht und Risiko, Frankfurt am Main: Vittorio Klostermann, 1993, p. 160). Son precisamente estos dos últimos aspectos de tinte subjetivo los que condicionarán decisivamente determinadas opciones penales que, sin duda, van más allá de lo que podría considerarse una respuesta razonable en términos de contención penal a la presencia objetiva de nuevos riesgos. Cabe precisar, por otra parte, que si bien para BECK el centro de atención era efectivamente el dato objetivo de la masificación de los procesos de riesgo sus consecuencias sociales, económicas y políticas, la noción de inseguridad subjetiva no es ajena a este autor. Así, BECK habla ya de la comunidad del miedo como característica de la sociedad del riesgo frente a la comunidad de la miseria propia de la sociedad de clases a la que contrapone aquélla (BECK, La sociedad del riesgo, pp. 55 y 56); y señala en varias ocasiones el enorme potencial político de la sensación colectiva de inseguridad (entre otras, pp. 86-87 y 282).
} 
naturaleza, como pueden ser los relacionados con la inseguridad ciudadana o el terrorismo, conformando todos ellos un modelo de Derecho penal de difícil consenso terminológico, a la vista de la diversidad de ámbitos y enfoques sobre la criminalidad que acaba por comprender.

En estas páginas, no me propongo el estudio de cada uno de los marcos conceptuales relacionados, de una $\mathrm{u}$ otra forma, con la cuestión planteada y utilizados hasta hoy (Derecho penal del riesgo, Derecho penal moderno, Derecho penal de la seguridad ciudadana, Derecho penal de la emergencia, Derecho penal del enemigo, Derecho penal preventivo, Derecho penal de policía, etc.), ni mucho menos de la relación que pueda darse entre los mismos. Cada uno de estas expresiones responde a una aproximación o a una problemática específica con razones y explicaciones que justificarían ya de por sí un análisis individualizado ${ }^{10}$.

Como he apuntado, a la vista del contexto social, político y económico global, me interesa, por el contrario, centrar la atención en la orientación del Derecho penal a la consecución de la sensación de seguridad individual y colectiva de la población. Para ello, parto del concepto de seguridad subjetiva y su correlativo de inseguridad desarrollado en el contexto del debate sobre la sociedad del riesgo - insisto, entendida como percepción social del riesgo-, aunque extendiéndolo a cualquier miedo social ${ }^{11}$. Por consiguiente, cuando me refiera a la "sociedad del riesgo" lo haré en el sentido más amplio utilizado ya entrado el siglo XXI, fruto de la propia evolución de las tesis de Ulrich Beck. En el ámbito de la doctrina penal, un ejemplo de la progresiva ampliación del concepto es Winfried Hassemer. Este autor, que fue clave en el inicio del debate sobre el Derecho penal del riesgo cuando éste se refería sustancialmente a los riesgos derivados de la técnica, hoy entiende que la "sociedad del riesgo" comprende también "las crisis financieras mundiales, la contaminación ambiental, la migración fuera de control, la violencia juvenil e infantil, el desempleo pavoroso y la movilidad social en descenso, el terrorismo y el crimen organizado o la guerra y los peligros de la guerra" ${ }^{\text {"12 }}$. En realidad, el tiempo no ha hecho sino dar la razón a Jesús-María Silva Sánchez, quien en esa época abordaba ya la "sociedad del riesgo" como "sociedad del miedo", anticipándose así a la magnitud que el fenómeno ha alcanzado en la actualidad. ${ }^{13}$

\footnotetext{
${ }^{10}$ Como es lógico, no puede dejarse constancia aquí de la amplia bibliografía existente sobre cada uno de estos conceptos. Por su valor de síntesis y perspectiva temporal de las distintas posturas doctrinales ante la sociedad del riesgo, véase JIMÉNEZ DÍAZ, M.J., "Sociedad del riesgo e intervención penal", Revista Electrónica de Ciencia Penal y Criminología 16-08 (2014), pp. 08:1-08:25.

${ }^{11}$ No debe confundirse, por consiguiente, este concepto de seguridad/inseguridad subjetiva con el más acotado significado habitual de la expresión en los ámbitos de la criminología y la victimología, especialmente con relación a la seguridad ciudadana, en los que por inseguridad subjetiva se entiende el temor individual o colectivo a ser víctima de un delito.

${ }^{12}$ HASSEMER, W., "La medida de la Constitución", en: CARBONELL MATEU, J.C.; GONZÁLEZ CUSSAC, J.L.; ORTS BERENGUER, E. (Dirs.), Constitución, Derechos Fundamentales y Sistema Penal, Tomo I, Valencia: Tirant lo Blanch, 2009, p. 978.

${ }^{13}$ SILVA SÁNCHEZ ( La expansión, cit. nota $\mathrm{n}^{\circ}$ 3, pp. 24 y 40). Este autor mencionaba la criminalidad callejera, la violencia familiar o el acoso sexual como otras fuentes de miedo colectivo que contribuyen a la consideración de la seguridad como pretensión social y, con ello, a la expansión del Derecho penal. Ponía de relieve asimismo, que la mayoría de los distintos ámbitos que sufren la expansión de la intervención punitiva pueden ser englobados bajo el concepto de "criminalidad de los poderosos", en la que el ciudadano tiende
} 
MARQUÈS I BANQUÉ, Maria. "Problemas de legitimación del Derecho penal del miedo".

En cuanto a la estructura del trabajo, con el objetivo de centrar el análisis, realizaré en primer lugar algunas consideraciones en torno al concepto de seguridad subjetiva y de "Derecho penal del miedo". A continuación, abordaré los conceptos de instrumentalización política, funcionalización (ilegítima) del Derecho penal y Derecho penal simbólico. Estos conceptos, tan ampliamente tratados por la doctrina tiempo atrás, forman parte hoy de la matriz interpretativa a partir de la que debería abordarse cualquier reforma penal.

Por consiguiente, y ello es importante a efectos de una adecuada delimitación del objeto de este trabajo, no abordaré en esta ocasión: a) la discusión filosófica que se encuentra en el fondo del debate aquí planteado, que no es otra que la vieja tensión libertad-seguridad; b) la compleja cuestión de si este tipo de seguridad constituye un derecho y su relación con la teoría del bien jurídico, problema distinto al planteado y que merece ser objeto de un análisis específico en otro lugar; y c) la aproximación que se hace a estas mismas cuestiones desde la perspectiva de la Filosofía Política, abordando el conflicto entre prevención y garantías desde la confrontación comunitarismo-liberalismo (y sus consecuencias en el ámbito de la teoría de la pena), sin perjuicio de tener presentes las observaciones hechas desde esta óptica por otros autores, en la medida que forman parte de ese contexto teórico más amplio desde el que debería afrontarse cualquier discurso de legitimación del Derecho penal. ${ }^{14}$

\section{La orientación a la seguridad subjetiva como característica del Derecho penal del miedo}

Si bien desde una perspectiva histórica la cuestión de la seguridad subjetiva se encuentra ya en el fondo ideológico que en la primera mitad del s. XX alumbró la llamada Defensa Social, explícitamente anclada en la idea de defender a la mayoría "buena y honrada" del creciente peligro encarnado en los desviados, es con la "sociedad del riesgo" cuando la relación entre la creciente percepción del peligro por parte de la ciudadanía y la progresiva concepción de la seguridad como necesidad social, cobra protagonismo convirtiéndose en objeto de estudio de varias disciplinas, y muy significativamente, de la Sociología y la Criminología ${ }^{15}$.

más a verse como víctima potencial que como posible delincuente, lo cual "redunda en la conformación de un consenso restrictivo en cuanto al alcance de los riesgos permitidos”(p. 41). Algo más tarde, destacó también la generalización de las preocupaciones sociales y sus consecuencias en materia penal, MENDOZA BUERGO, B., El Derecho penal en la sociedad del riesgo, Madrid: Civitas, 2001, p. 159.

${ }^{14}$ Muy significativamente, ALCÁCER GUIRAO, R., "Los fines del Derecho penal. Una aproximación desde la filosofía política", Anuario de Derecho Penal y Ciencias Penales 1998, pp. 365-587. Del mismo, "Prevención y garantías: conflicto y síntesis", DOXA núm. 25 (2002), pp. 139-175. Entiende también necesario tener en cuenta esta aproximación como punto de partida, DEMETRIO CRESPO, E., "El 'Derecho penal del enemigo' darf nicht sein! Sobre la ilegitimidad del llamado 'Derecho penal del enemigo' y la idea de seguridad", en: VV.AA, El Derecho penal frente a la inseguridad global, Albacete: Ediciones Bomarzo, 2007, pp. 125-127. Una aproximación al binomio libertad-seguridad desde la óptica de la legitimación del Derecho penal del riesgo en términos de utilidad social, puede verse en GÓMEZ MARTÍN, V., "Libertad, seguridad y "sociedad del riesgo"”, en: GÓMEZ MARTíN, V. (Coord.), La Política Criminal en Europa, Barcelona: Atelier, 2004, pp. 59-90.

${ }^{15}$ Señala NAUCKE que, en realidad, la cuestión de si es posible la consecución de la seguridad a través del Derecho penal es muy anterior al S. XX. Véase un breve repaso histórico de la idea de seguridad desde Hobbes en NAUCKE, W., "La robusta tradizione del diritto penale della sicurezza: illustrazione con intento critico", en: DONINI, M.; PAVARINI, M. (Eds.), Sicurezza e Diritto Penale, Bologna: Bononia University 
La seguridad como valor social es consecuencia de la colectiva sensación de inseguridad producida por la existencia en las sociedades modernas de múltiples y complejas fuentes de riesgo cuyo control escapa a las capacidades individuales de sus miembros. Dicho fenómeno, que como ya he indicado tiene sus raíces en la aparición de la sociedad industrial y en los peligros derivados del tráfico rodado, se ha intensificado decisivamente incluyendo múltiples fuentes de riesgo. Señalaba ya Luis Arroyo Zapatero cuando el debate sobre la "sociedad del riesgo" se encontraba en su momento más vivo, que mientras una buena parte de los riesgos derivados de los procesos técnicos tradicionales han sido interiorizados y asumidos colectivamente -"ya sea como consecuencia de la 'instalación' de sistemas complejos de prevención e indemnización, ya sea por resultar el interés individual en asumir el riesgo masivamente superior al de la eliminación del mismo, como es el caso del riesgo del tráfico automovilístico"- los riesgos derivados de los procesos de alta tecnología, como los relativos a la energía nuclear u otros procesos químicos, son riesgos no asumidos y, por ello, rechazados total o parcialmente, siendo el criterio de la aparente controlabilidad, que cabe predicar de los primeros pero no de los segundos, lo que parece distinguir la conciencia social entre unos procesos y otros a la hora de asumir sus riesgos ${ }^{16}$.

La "sociedad del riesgo" se caracteriza, por tanto, como una sociedad en la que los procesos de riesgo se multiplican y se hacen más complejos, sin que ello se corresponda con una interiorización de los mismos por parte de sus miembros, los cuales, lejos de aceptar los nuevos riesgos, se instalan en la conciencia de la inseguridad y sienten, cada vez más, la seguridad como una necesidad cuya satisfacción cabe exigir al Estado como responsable del control de dichos riesgos y garante de la seguridad colectiva.

No obstante, pronto se observó que la reacción social ante los riesgos que acabo de describir no siempre se corresponde con la realidad objetiva, lo que llevó a la doctrina a hablar de la "Paradoja de la necesidad de seguridad" (Paradoxie des Bedürfnisses nach Sichercheit $)^{17}$. Dicha paradoja describe cómo a pesar del aumento de la seguridad objetiva en muchos ámbitos, entendida ésta como el efectivo control de riesgos, sigue incrementándose la inseguridad subjetiva como percepción social. En este sentido,

Press, 2011, pp. 79-89. Con relación a la Sociología y la Criminología, entre las muchas obras de referencia existentes, véase un amplio análisis del caso estadounidense en SIMON, J., Governing through Crime: How the War on Crime Transformed American Democracy and Created a Culture of Fear, Oxford-New York: Oxford University Press, 2007.

${ }^{16}$ ARROYO ZAPATERO, L., "Derecho y riesgo", Revista de Responsabilidad Civil y Seguro, núm. 8, octubre-diciembre 1995, p. 60. En el mismo sentido, SILVA SÁNCHEZ, La expansión, cit. nota n 3, p. 26: "Así, tras la revolución de los transportes, la actual revolución de las comunicaciones da lugar a un vértigo derivado de la falta -sentida y probablemente asimismo real- de dominio del curso de los acontecimientos, que no puede sino traducirse en términos de inseguridad".

${ }^{17}$ HERZOG, F., Gesellschaftliche Unsicherheit und strafrechtliche Daseinsvorsorge, Heidelberg: v. Decker, 1991, pp. 52 y 53, recogiendo la teoría del sociólogo Franz-Xaver Kaufmann. Todavía desde la perspectiva de la sociología puede verse también ROCHÉ, S., Le sentiment d'insécurité, Paris: Presses Universitaires de France, 1993, pp. 101 y ss. La existencia de "miedos injustificados" es señalada asimismo como característica de la sociedad del riesgo por SEELMANN, K., "Risikostrafrecht", Kritische Vierteljahresschrift für Gesetzgebung und Rechtswissenschaft 1992, p. 453, y por PRITTWITZ, C., "Funktionalisierung des Strafrechts”, Strafverteidiger 9/1991, p. 438. En España, SILVA SÁNCHEZ, La expansión, cit. nota n 3, pp. 25-26 y 30. 
MARQUÈS I BANQUÉ, Maria. "Problemas de legitimación del Derecho penal del miedo".

observaba ya Beck que los riesgos son reales cuando los seres humanos los viven como reales $^{18}$. En efecto, a pesar de ser muchos más los mecanismos de prevención de riesgos con los que se cuenta hoy en día, se ha observado cómo ello no ha contribuido a disminuir la percepción colectiva del peligro, de forma que la sensación social de inseguridad, lejos de disminuir, sigue aumentando. Este incremento de la inseguridad subjetiva se explica, a su vez, con la descripción de un círculo vicioso: la insistente demanda de protección y seguridad genera más complejidad en el tratamiento de las fuentes de riesgo y las estructuras sociales. La complejidad social, por su parte, es la causa de más dificultades en orden a la asunción de los procesos de riesgo y sus mecanismos de control, constituyendo dichas "dificultades de orientación" (Orientierungsschwierigkeiten), la base de nuevas inseguridades.

De lo expuesto hasta aquí se deriva la necesidad de diferenciar los dos aspectos, objetivo y subjetivo, del concepto de seguridad ${ }^{19}$. La idea de seguridad como exigencia normativa por parte de la Sociedad no residirá únicamente en la objetiva protección frente a los nuevos riesgos sino, asimismo, en la consecución de una percepción colectiva de tranquilidad o "sensación de seguridad". "La inseguridad deja de significar mero peligro, para pasar a describir también una sensación o estado de la conciencia" ${ }^{20}$. La toma de conciencia por parte del legislador de la doble dimensión objetiva y subjetiva del concepto de seguridad tiene importantes consecuencias normativas a partir del momento en que, por las razones que se explicarán seguidamente, se toma la decisión de contemplar a ambas como objetivo de la intervención legislativa apartándose de su exclusiva e inicial orientación a la eliminación de los riesgos.

En efecto, sabemos que el consenso social en torno a la necesidad de seguridad se traduce en el ámbito normativo en insistentes exigencias preventivas ${ }^{21}$. La seguridad objetiva se

\footnotetext{
${ }^{18}$ Y añadía: "Pero si son reales en este sentido, trastornan por completo el tejido de competencias sociales, políticas y económicas" (BECK, La sociedad del riesgo, cit. nota $\mathrm{n}^{\circ}$ 9, p. 86). Desde el ámbito de la Sociología, también LUHMANN consideraba el problema de la percepción y aceptación de los riesgos como un problema ante todo social de indudables consecuencias en el ámbito de la política (LUHMANN, N., Soziologie des Risikos, Berlin-New York: de Gruyter, 1991, p. 11 y pp. 155 y ss.).

${ }^{19}$ Algo que las ciencias sociales vienen haciendo desde hace tiempo cuando se trata de abordar el tema de la sociedad del riesgo. Así, por ejemplo, PUY, A., Percepción social de los riesgos, Madrid: Mapfre, 1995, quien ya distinguía entre riesgo objetivo y subjetivo y consideraba dicha diferenciación el elemento que "precisamente dio lugar al surgimiento y auge de los estudios sobre percepción social del riesgo en los años setenta" (p. 15). El concepto de seguridad subjetiva entendido como "miedo a la criminalidad" se plantea así mismo en el marco del debate sobre seguridad ciudadana. Así ROCHÉ, Le sentiment, cit. nota n ${ }^{\circ} 17$, passim.

${ }^{20}$ BECK, La sociedad del riesgo, cit. nota $\mathrm{n}^{\circ}$ 9, p. 52.

${ }^{21}$ Extremo que llevó a la doctrina en su día a calificar el Estado contemporáneo de "Estado de la prevención" (DENNINGER, E., "Der Präventions-Staat", Kritische Justiz 21, 1988-1, pp. 1-15) o "Estado de la seguridad" (HIRSCH, J., Der Sicherheitsstaat. Das "Model Deutshcland," seine Krise und die neuen sozialen Bewegungen, Frankfurt am Main: Europäische Verlagsanstalt, 1980), siendo ambos conceptos descritos por BARATTA como "la forma política que asume la 'sociedad del riesgo' (...) en el que la producción normativa y los mecanismos decisionales también tienden a reorganizarse como respuesta a una situación de emergencia estructural" (BARATTA, A., "Funciones instrumentales y simbólicas del Derecho penal: una discusión en la perspectiva de la Criminología crítica", Pena y Estado núm. 1, septiembre-diciembre 1991, p. 45). La caracterización del Estado como Estado de prevención y la consecución de seguridad a través del Derecho penal, es todavía objeto de reflexión en Italia. Un ejemplo en DONINI, M., "Sicurezza e Diritto Penale. La sicurezza come orizzonte totalizzante del discorso penale“, en: DONINI, M.; PAVARINI, M. (Eds.), Sicurezza e Diritto Penale, Bologna: Bononia University Press, 2011, pp. 11-32.
} 
somete a las exigencias de una seguridad subjetiva más vivamente sentida como necesidad: para la población parece no importar tanto que los sistemas de control de las fuentes de riesgo existan y sean realmente eficaces como que así lo pueda percibir. Ello explica que en los ámbitos de riesgo el recurso al Derecho penal pueda excederse -como de hecho ocurrede los límites que una intervención debidamente orientada por los principios informadores del ius puniendi aconsejaría.

El legislador se ve abocado a la búsqueda de instrumentos contundentes y formas de intervención con capacidad de impacto social. El Derecho penal y en concreto la protección penal anticipada, aparece rápidamente como medio idóneo a la consecución de este fin. Hassemer hablaba en este sentido del "paradigma preventivo" como nota característica del moderno Derecho penal. Según este autor, el legislador canaliza la imperiosa necesidad de encontrar soluciones a los riesgos sociales a través de la prevención normativa, lo cual supone el control de los riesgos mediante la creación de nuevos tipos penales, la ampliación de los existentes o la intensificación de los instrumentos de averiguación ${ }^{22}$. Por su parte e introduciendo expresamente el elemento subjetivo en su afirmación, advertía Felix Herzog que la expansión de los tipos de peligro, y en concreto de los tipos de peligro abstracto, podía

"ser interpretada, si más no parcialmente, como una reacción a las inseguridades derivadas de las innovaciones, el aumento de la complejidad, los cambios estructurales o las transformaciones operadas ya sea en el ámbito económico o tecnológico, en el orden cultural o en el consenso básico ético-moral y político"23.

Junto a la protección de bienes jurídicos aparece la seguridad subjetiva como objetivo de la intervención penal, con los problemas que en cuanto a la contención de la misma esto conlleva. El principio de intervención mínima se ve indudablemente cuestionado cuando es la minimización de la inseguridad subjetiva lo que se pretende, pues ésta, como sensación e impulso irracional, no tiene límites ${ }^{24}$. A la "paradoja de la necesidad de seguridad", hay que añadir la indiscutible influencia que ejercen los medios de comunicación en la pérdida de la sensación de seguridad en un mundo moderno y globalizado ${ }^{25}$. La consiguiente

\footnotetext{
${ }^{22}$ Reacción que calificaba, por otra parte, como vulneradora de derechos fundamentales y de libertad de los ciudadanos. HASSEMER, W. , "Perspektiven einer neuen Kriminalpolitik", Strafverteidiger 1995, p. 489.

${ }^{23}$ HERZOG, Gesellschaftliche, cit. nota no 17, p. 54.

${ }^{24}$ En parecido sentido STORTONI, L., "El riesgo procedente del desconocimiento tecnológico" (trad. de C. Méndez Rodríguez), Responsa Iurisperitorum Digesta, Vol. III, 2000, p. 100, calificándolo de "peligrosa espiral emotiva e irracional".

${ }^{25}$ En España, GARCÍA ARÁN, M., "Delincuencia, inseguridad y pena en el discurso mediático", en MUÑOZ CONDE, F. (Dir.), Problemas actuales del Derecho Penal y la Criminología, Valencia: Tirant lo Blanch, 2008, pp. 85-113; BAUCELLS LLADÓS, J., "Medios de comunicación y populismo punitivo. Revisión teórica del concepto y análisis de la reforma penal en materia de hurto", Revista Penal núm. 27, 2011, pp. 111-131; FUENTES OSORIO, J.L., "Los medios de comunicación y el Derecho penal", Revista Electrónica de Ciencia Penal y Criminología, núm. 07-16 (2005); CASTAÑO TIERNO, P., “¿Otra polítca penal es posible? Un estudios sobre la viabilidad de una política criminal alternativa al populismo punitivo“, Estudios Penales y Criminológicos vol. XXXIV (2014), pp. 561-638; CUERDA RIEZU, A., "Los medios de comunicación y el Derecho penal", en: ARROYO ZAPATERO, L.A.; BERDUGO GÓMEZ DE LA TORRE, I. (Coords.), Homenaje al Dr. Marino Barbero Santos: 'in memoriam', Vol. 1, Cuenca: Ediciones de la Universidad de Castilla-La Mancha; Salamanca: Ediciones de la Universidad de Salamanca, 2001, pp. 187-
} 
MARQUÈS I BANQUÉ, Maria. "Problemas de legitimación del Derecho penal del miedo".

confirmación de la idea del Estado como garante de la seguridad en todas sus dimensiones, intensifica las expectativas sociales de una intervención estatal rápida, eficaz, y principalmente, tranquilizadora. A ello debe todavía añadirse el discurso en ocasiones sesgado de los responsables políticos en materia de seguridad, lo que nos lleva a la cuestión de la instrumentalización política del Derecho penal y al tan denunciado electoralismo al que me referiré más adelante.

Un Derecho penal cuyos criterios de intervención se determinan en función de irracionales necesidades subjetivas -el apaciguamiento de miedos individuales por más que extendidos socialmente-, es un Derecho penal que experimenta una profunda transformación no sólo en sus presupuestos sino en todo su conjunto. A esta conclusión, profusamente estudiada por la doctrina, llegaba Hassemer cuando afirmaba que "las así creadas y en su concreción experimentadas responsabilidades, los intereses de minimizar la inseguridad de una 'sociedad del riesgo' y de dirigir los procesos complejos, han afectado no solo a la política criminal sino asimismo a la teoría penal y a la doctrina del bien jurídico" 26 .

Como tendré ocasión de desarrollar en las siguientes páginas, por "Derecho penal del miedo" entiendo, en suma, el fenómeno -no siempre explícito- por el que el Derecho penal en la "sociedad del riesgo" deja de tener como única función la protección de bienes jurídicos para pasar a orientarse también a la seguridad subjetiva. A continuación me centraré en tres de sus consecuencias: la instrumentalización política, la funcionalización ilegítima del Derecho penal, y la legislación penal simbólica.

\section{La instrumentalización política del Derecho penal}

En nuestro tiempo no existe grupo político que no se autocalifique de paladín de la seguridad objetiva y subjetiva. La demanda de respuestas rápidas y contundentes por parte de una población que se siente insegura ante la complejidad del mundo globalizado, se traduce en llamativos actos de intervención penal cuya idoneidad radica, en muchas ocasiones, más en la inmediata sensación de resolución del problema que en criterios de eficacia material. El recurso al Derecho penal como reacción política a determinados conflictos o exigencias sociales es una cuestión recurrente en Derecho penal, analizada por la doctrina en varios ámbitos, de entre los cuales cabe destacar, en un primer momento, los relativos a la actividad económica y el medio ambiente, y con posterioridad, todos aquellos

207; BRANDARIZ GARCÍA, J.A., "Nuevos riesgos, nuevas ansiedades y expectativas sociales en materia de seguridad ante el delito", en: FARALDO CABANA, P., (Dir.), Derecho penal de excepción. Terrorismo e inmigración, Valencia: Tirant lo Blanch, 2007, pp. 153-154. Como señala este último autor, la referencia a los media en el proceso de colectivización del miedo, incluye tanto los medios de comunicación propiamente dichos en su función informadora (prensa, radio y televisión), como toda la industria del entretenimiento (p. 149). En el mismo sentido, ya con anterioridad BARATA, F., "Las nuevas fábricas del miedo. Los mass media y la inseguridad ciudadana" en: MUÑAGORRI LAGUÍA, I. (Coord.), La protección de la seguridad ciudadana, Oñati : The Oñati International Institute for the Sociology of Law, 1995, pp. 83-94. El papel de los medios de comunicación en el proceso de creación de una ley penal es destacado por DÍEZ RIPOLLÉS, J.L., "El bien jurídico protegido en un derecho penal garantista", NFP núm. 60, enero-abril 1999, p. 123. Con relación a la llamada teoría de la legislación, DEL MISMO, "Exigencias sociales y Política Criminal", Claves de Razón Práctica núm. 85 (1998), pp. 49 y 50.

${ }^{26}$ HASSEMER, W., "Derecho penal simbólico y protección de bienes jurídicos", Nuevo Foro Penal núm. 51 (1991), p. 28. 
vinculados a una idea más amplia de inseguridad (seguridad ciudadana, inmigración, terrorismo...). Así, por ejemplo, volviendo la vista atrás, Peter-Alexis Albrecht consideraba el Derecho penal económico como fruto principalmente de la presión psicológica y política que sufre el legislador, y criticaba el Derecho penal del medio ambiente en la medida en que se pretende que éste resuelva los conflictos de intereses no resueltos en el plano político $^{27}$.

Concebir el Derecho penal como instrumento para lograr la confianza de los ciudadanos es practicar la tan denunciada "huida al Derecho penal"28. El fenómeno de la instrumentalización política del Derecho penal lejos de ser fruto de la construcción doctrinal encuentra su origen en determinadas actitudes o inercias del legislador, como ya pusiera de manifiesto Claus Roxin con motivo del análisis de las causas de la ola de criminalización que tuvo lugar en Alemania con posterioridad al Alternativentwurf, contradiciéndose así uno de los principios políticocriminales reclamados por el mismo como fuera el de fragmentariedad y ultima ratio ${ }^{29}$.

Ante la necesidad de resolver los problemas sociales, el legislador tiende a buscar el mecanismo más convincente para la ciudadanía a un coste más bajo. Las consecuencias de esta actitud de "comodidad" por parte del Estado a la hora de encarar los conflictos y necesidades que está llamado a resolver, pueden terminar por ser, por un lado y como ha indicado Juan María Terradillos, la de "una situación de hecho de desprotección programada"30; y por otro lado, la de "administrativización" del Derecho penal en el sentido descrito por Alessandro Baratta de alejamiento de las normas penales de los requisitos de abstracción y generalidad propios de la ley, con la consiguiente transformación del Derecho penal "en un instrumento de administración de situaciones

27 ALBRECHT, P-A., "Das Strafrecht auf dem Weg vom liberalen Rechtsstaat zum sozialen Interventionsstaat - Entwicklungstendenzen des materiellen Strafrechts", 12.Strafverteidigertag (1989), p. 40 y 43. En materia económica debe tenerse en cuenta, sin embargo, la relación entre globalización y Derecho penal, en la medida que como señala TERRADILLOS BASOCO, en coherencia con la idea de desregulación estrechamente vinculada a la de globalización, la globalización económica, más que fomentar la expansión penal, la inhibe al menos parcialmente, "dando lugar a una doble tendencia político-criminal definida por el absentismo -en áreas que puede disciplinar el mercado de acuerdo con el contratante más fuerte- y la rígida intervención -cuando se trata de asegurar la pax publica requerida por ese mismo mercado" (TERRADILLOS BASOCO, J.M., "Globalización, administrativización y expansión del Derecho penal económico", en: TERRADILLOS BASOCO, J.; ACALE SÁNCHEZ, M. (Coords.), Temas de Derecho penal económico, Madrid: Trotta, 2004, pp. 222-225).

${ }^{28}$ ROXIN, C., "Franz von Liszt y la concepción políticocriminal del Proyecto Alternativo", en: ROXIN, C., Problemas básicos del Derecho penal (trad. de D.M. Luzón Peña), Madrid: Reus, 1976, p. 45. En España, por todos QUINTERO OLIVARES, G., La justicia penal en España, Pamplona: Aranzadi, 1998, pp. 34-36. En Italia, el fenómeno de la hipertrofia penal a la que conduce la "huida al Derecho penal" y sus distintas causas fueron analizadas críticamente por la doctrina, siendo frecuente el uso del término panpenalizzazione (o panpenalismo) para designarlo. En este sentido, entre otros, MUSCO, E., "A proposito del diritto penale 'comunque ridotto", en: PEPINO, L. (Ed.), La riforma del diritto penale, Milano: Franco Angeli, 1993, pp. 170-183; así como, extensamente con anterioridad, PALIERO, C.E., Minima non curat praetor. Ipertrofia del diritto penale e decriminalizzazione dei reati bagatellari, Padova: CEDAM, 1985.

${ }^{29}$ ROXIN, C., "El desarrollo de la política criminal desde el Proyecto Alternativo" (trad. de J. Queralt), en: MIR PUIG, S. (Ed.), Política Criminal y Reforma del Derecho penal, Bogotá: Temis, 1982, pp. 9-11.

${ }^{30}$ TERRADILLOS BASOCO, J., "Función simbólica y objeto de protección del Derecho penal", Pena y Estado núm.1, septiembre-diciembre 1991, p. 9. 
MARQUÈS I BANQUÉ, Maria. "Problemas de legitimación del Derecho penal del miedo".

particulares, de riesgos excepcionales; en otras palabras, en un instrumento de respuesta contingente y puntual a 'emergencias' concretas" 31 . Con lo cual, como afirma José Luis Díez Ripollés,

“(...) entramos en el reino del proceder legislativo declarativo-formal, cuya pretensión fundamental es la de plasmar en la norma legal del modo más fiel y contundente posible el estado actual de las opiniones colectivas sobre una determinada realidad social conflictiva, y que está ayuno de cualquier consideración sobre la medida en que la norma en cuestión puede colaborar a la solución del problema" ${ }^{32}$.

La orientación del Derecho penal a la satisfacción de intereses sociopolíticos no es desde luego exclusiva del Derecho penal del miedo. En efecto, se ha visto como la tendencia a la "huida al Derecho penal" se configura como una vía de respuesta política a las demandas sociales. Las exigencias de intervención que pueden surgir de la colectividad se multiplican en una sociedad del riesgo en la medida en que se multiplican y se hacen más visibles los procesos de peligro incontrolables individualmente $\mathrm{y}$, con ellos, las fuentes de preocupación e inestabilidad psíquica de la población. La inseguridad y el miedo que resultan de la percepción de dichas fuentes de riesgo generan impaciencia en cuanto a la reacción estatal e imposibilitan, o por lo menos dificultan, respuestas no solo razonables sino también debidamente razonadas. Es indudable que los límites del ius puniendi (como el principio de intervención mínima, el de subsidiariedad, el de fragmentariedad o el de exclusiva protección de bienes jurídicos) encontrarán serias dificultades para operar en procesos legislativos "de urgencia" guiados por la voluntad de pacificación de ánimos e inquietudes colectivas y detrás de ello, de renovación de la confianza electoral ${ }^{33}$. Tal y como ha señalado algún autor, en un Derecho penal instrumentalizado "la política criminal deberá cumplir dos papeles: servir a los intereses electorales y por tanto a los intereses de los partidos y aparecer como 'solucionando' el problema" 34 , con lo que, en definitiva, como advierte Juan Carlos Carbonell Mateu, todo ese conjunto de principios que deberían obligar

31 BARATTA, "Funciones instrumentales", cit. nota no 21, p. 44. La "administrativización” del Derecho penal, por la cual, a tenor de este autor, también debe entenderse la tendencia cada vez más patente al carácter accesorio o secundario de las leyes penales, es descrito como "fenómeno general en el que se inscribe este devenir evanescente de la línea de distinción entre función defensiva y función promocional del concepto de bien jurídico" (p. 43). Por su parte, señala TERRADILLOS BASOCO que la administrativización del Derecho penal convierte el Derecho penal de protección de bienes jurídicos en un Derecho de gestión de riesgos (TERRADILLOS BASOCO, “Globalización”, cit. nota n 27, p. 220).

${ }^{32}$ DÍEZ RIPOLLÉS, J.L., "El derecho penal simbólico y los efectos de la pena”, Actualidad Penal, núm. 1, semana del 1 al 7 de enero de 2001, p. 3.

33 BRICOLA, F., "Tecniche di tutela penale e tecniche alternative di tutela", en: DE ACUTIS, M.; PALOMBARINI, G. (Eds.), Funzioni e limiti del diritto penale. Alternative di tutela, Padova: CEDAM, 1984, pp. 3-84, señalaba ya las repercusiones que la tendencia a considerar el Derecho penal como el instrumento más idóneo en una sociedad en crisis tenía sobre los principios de subsidiariedad y fragmentariedad. Con relación al oportunismo político y la "ideología oculta" de las reformas penales de 2003 en España, véase por todos QUINTERO OLIVARES, G., "La politica criminale del 'centro-destra' spagnolo: le riforme penali dell'anno 2003”, Critica del Diritto N. 2-3-4, Aprile-Dicembre 2003, pp. 159-163.

${ }^{34}$ HERZOG, F., "Límites al control penal de los riesgos sociales (Una perspectiva crítica ante el Derecho Penal de peligro)", Anuario de Derecho Penal y Ciencias Penales Vol. 46, N 1 (1993), p. 322, comentando la tesis de STANGL sobre el valor de cambio político del Derecho penal. En parecido sentido DÍEZ RIPOLLÉS, "Exigencias sociales”, cit. nota n 25, pp. 48 a 51. 
a consensuar el uso del Derecho penal, lo que finalmente no siempre impide, es que se consensue su abuso ${ }^{35}$.

La instrumentalización política del Derecho penal que resulta de la orientación a la seguridad subjetiva puede ser señalada como una forma de funcionalización ilegítima del mismo. Tal afirmación requiere, sin embargo, de algunas consideraciones. Por un lado, es preciso establecer en qué términos cabe considerar legítima la relación entre Derecho penal y política y cuáles son en todo caso sus límites, en aras a una correcta comprensión del concepto de instrumentalización política. Por otro lado, es también necesario establecer qué se entiende por funcionalización legítima e ilegítima del Derecho penal desde la óptica de un Derecho penal garantista. A esta última cuestión dedicaré el apartado tercero, centrándome a continuación en la relación entre Derecho penal y política.

El concepto de Derecho penal pone ya de manifiesto la indiscutible dimensión política del mismo. El Derecho penal objetivo o conjunto de normas de Derecho público que describen delitos y los castigan con una pena o medida de seguridad, presupone el reconocimiento del llamado ius puniendi o Derecho penal subjetivo. La potestad punitiva del Estado entendida como facultad para actuar el Derecho penal objetivo, supone la "expresión de un acuerdo democrático tomado en uso de las facultades conferidas por la ciudadanía y que está dirigido a todos bajo la amenaza de sanción" "36. En términos generales puede decirse que el Derecho penal es un instrumento político, en la medida que se encuentra al servicio de la política criminal, y ésta no es sino una parte de la política general del Estado ${ }^{37}$. No en vano sigue insistiéndose en que la patente conexión entre política y Derecho penal sobre la que algunos autores hicieron especial incidencia a finales del franquismo en España, "no representa sólo una guía para la interpretación histórica, ni tampoco una verdad puramente formal, sino que puede y debe ser entendida como una clave de la configuración del sistema penal de un país" ${ }^{38}$, por lo que en un discurso de legitimación del Derecho penal no debe perderse nunca de vista.

La misma existencia del Derecho penal, por consiguiente, se configura ya como una decisión de contenido esencialmente político que además, en el marco del Estado de Derecho, es de naturaleza democrática. Es precisamente el origen democrático de la potestad punitiva lo que impregna los dos momentos de su ejercicio, el legislativo y el aplicativo, confiriéndoles una serie de límites de obligada observancia. Me refiero, como es sabido, a los principios informadores del Derecho penal y a los límites que de ellos se derivan para el ejercicio de la potestad punitiva del Estado ya sea en su fase regulativa o aplicativa, como son los principios de legalidad, exclusiva protección de bienes jurídicos, intervención mínima, culpabilidad, humanidad de las penas y dignidad de las personas.

\footnotetext{
${ }^{35}$ CARBONELl MATEU, J. C., "Reflexiones sobre el abuso del Derecho penal y la banalización de la legalidad", en: ARROYO ZAPATERO, L.A.; BERDUGO GÓMEZ DE LA TORRE, I. (Coords.), Homenaje al Dr. Marino Barbero Santos: 'in memoriam', Vol. 1, Cuenca: Ediciones de la Universidad de Castilla-La Mancha; Salamanca: Ediciones de la Universidad de Salamanca, 2001, p. 135.

${ }^{36}$ QUINTERO OLIVARES, G., Manual de Derecho penal, $3^{\mathrm{a}}$ Ed., Cizur Menor: Aranzadi, 2002, p. 40.

${ }^{37}$ Por todos, CARBONELL MATEU, "Reflexiones", cit. nota n 35 , p. 135.

${ }^{38}$ GARCÍA RIVAS, N., El poder punitivo en el Estado democrático, Cuenca: Universidad de Castilla-La Mancha, 1996, p. 43.
} 
MARQUÈS I BANQUÉ, Maria. "Problemas de legitimación del Derecho penal del miedo".

El problema radica en que los principios limitadores del ius puniendi tienen distinta caracterización y diferente grado de dificultad de ser percibidos y por tanto plasmados por parte del legislador. Es indudable que el grado de dificultad que entraña el respeto a la exigencia de Ley Orgánica derivada del contenido del principio de legalidad supone menor complejidad que la que implica el respeto a las exigencias del principio de exclusiva protección de bienes jurídicos o el respeto al principio de intervención mínima, en ambos casos de contenido esencialmente valorativo. Es por ello que entiendo pertinente partir de la distinción entre legitimidad formal y legitimidad material, la cual presupone un plus que expresa la conformidad de los preceptos penales, no sólo con los mecanismos democráticos de elaboración y promulgación de las leyes penales, sino con el contenido material del Derecho penal. Así, por ejemplo y en relación con el principio de exclusiva protección de bienes jurídicos, la tutela de valores o intereses que no puedan considerarse incluidos entre los mínimos esenciales para la convivencia y compartidos por esta razón por la mayoría de los ciudadanos, deberá ser considerada carente de legitimidad en su sentido material. De ahí la nota de "exclusividad" que se predica de la protección de bienes jurídicos, pues bien jurídico será, únicamente, aquel valor o interés que se haya hecho sentir como tal de forma mayoritaria por la colectividad a través de las vías políticas y jurídicas previstas para ello, debiendo de limitarse, el Derecho penal, a la protección de los mismos ${ }^{39}$. En cambio, la legitimidad formal de la configuración de bienes jurídicos a través de actos legislativos de naturaleza penal podrá afirmarse en la medida en que sean observados los mecanismos democráticos de participación ciudadana establecidos para la formación de la voluntad general $^{40}$.

Solamente respetando el origen democrático del ius puniendi en cada una de las fases de su ejercicio, se puede, por tanto, postular el Derecho penal como elemento estructurador político y social $^{41}$. La legitimidad del Derecho penal como instrumento para ordenar la

\footnotetext{
${ }^{39}$ Véase la postura del Tribunal Constitucional español en la STC 55/1996, de 28 de marzo, (RTC 1996155): "en el ejercicio de su competencia de selección de los bienes jurídicos que dimanan de un determinado modelo de convivencia social y de los comportamientos atentatorios contra ellos, así como de determinación de las sanciones penales necesarias para la preservación del referido modelo, el legislador goza, dentro de los límites establecidos en la Constitución, de un amplio margen de libertad que deriva de su posición constitucional y, en ultima instancia, de su específica legitimidad democrática. No sólo cabe afirmar, pues, que, como no puede ser de otro modo en un Estado social y democrático de Derecho, corresponde en exclusiva al legislador el diseño de la Política criminal, sino también que, con la excepción que imponen las citadas pautas elementales que emanan del Texto constitucional, dispone para ello de plena libertad".

${ }^{40}$ Esta forma de entender la legitimidad de la norma penal desde una doble perspectiva formal y material, nos conduce al discurso formulado por FERRAJOLI en torno a la distinción entre la "vigencia" de las normas (que hace referencia a la forma de los actos normativos y que depende de la conformidad o correspondencia con las normas formales sobre su formación) y su "validez" (o, si se trata de leyes, la 'constitucionalidad', que, por el contrario, tiene que ver con su significado o contenido y que depende de la coherencia con las normas sustanciales sobre su producción); o por BOBBIO, quien para explicar la estrecha vinculación entre la teoría de la norma jurídica y la teoría del poder político, pone de manifiesto el paralelismo existente entre los requisitos de "justicia" y "validez" de la norma y los de "legitimidad" y "legalidad" del poder, pudiéndose equiparar la "validez" de BOBBIO con la "vigencia" de FERRAJOLI (FERRAJOLI, L., "El derecho como sistema de garantías", Nuevo Foro Penal núm. 60 (enero-abril 1999), pp. 64-67, y más extensamente en Diritto e Ragione. Teoria del Garantismo Penale, 2a. ed., Roma-Bari: Laterza, 1990, pp. 197 y ss., y 904 y ss.; y BOBBIO, N., "Sobre el principio de legitimidad", en: RUIZ MIGUEL, A. (Ed.), Contribución a la teoría del Derecho, Valencia: Fernando Torres DL, 1980, pp. 307-316).

${ }^{41}$ QUINTERO OLIVARES, Manual, cit. nota $\mathrm{n}^{\circ} 36$, p. 42.
} 
convivencia y disciplinar voluntades tiene como presupuesto necesario la observación de los límites al ejercicio de la potestad punitiva. Esta dimensión política del Derecho penal explica la importancia de la Política Criminal cuya función básica es la de "expresar los fines del sistema penal y los límites de la intervención punitiva"42, orientando en todo momento las soluciones dogmáticas a la consecución de los primeros y al respeto de los segundos.

A partir del momento en que se reconoce el problema penal como un problema fundamentalmente social y político, la génesis de las leyes penales se convierte en objeto de necesario estudio por parte del penalista. Y por génesis de una ley, cabe entender todas aquellas fases de naturaleza sociopolítica que dan lugar a su promulgación y que deberán estar en todo caso presididas por los principios que informan la actividad legislativa penal de un Estado social y democrático de Derecho. Asimismo, el penalista deberá velar por el cumplimiento de los principios y garantías que informan la aplicación de la ley penal, cuya dimensión política en cuanto a manifestación del ejercicio del ius puniendi es también incuestionable.

Se perfilan así los legítimos contornos de la relación entre Derecho penal y política, en los que esta última constituye un instrumento para la construcción de un sistema penal orientado a determinados intereses político-criminales. La ilegitimidad de la misma puede afirmarse en el momento en que se invierten los términos convirtiéndose el Derecho penal en un instrumento al servicio del poder para la consecución de sus intereses políticos más inmediatos, a través de la influencia que la intervención penal ejerce sobre la conciencia colectiva en cuanto mecanismo de solución de problemas sociales. Y en la medida en que la seguridad subjetiva sea percibida por el legislador como un problema social, el Derecho penal se convierte, a sus ojos, en medio idóneo para su resolución.

Esta forma de proceder ha sido objeto de rechazo y críticas por parte de la doctrina partidaria de la contención penal en términos de un Derecho penal liberal y garantista, pues como afirma Díez Ripollés, "una sociedad compleja como la nuestra no puede legislar penalmente a partir de iniciativas gubernamentales o parlamentarias coyunturales, condicionadas cada vez más por la rentabilidad electoral de determinados estados de opinión con frecuencia pasajeros" $"$. Este mismo autor se ha expresado críticamente en relación con la inflexibilidad doctrinal en orden a acoger sentimientos y deseos, también de seguridad, que están legítimamente arraigados en la opinión pública ${ }^{44}$. Encontrar la justa medida en la que el Derecho penal y la Política Criminal deben ser permeables a la sensibilidad social, es un problema que no por viejo deja de ser menos complejo, y que afecta directamente a la legitimación del Derecho penal, como lo demuestra el también conocido debate sobre la "democracia de opinión" o la "legitimación ideológica", como concepto contrapuesto al de "democracia representativa".

\footnotetext{
${ }^{42}$ QUINTERO OLIVARES, Manual, cit. nota $\mathrm{n}^{\mathrm{o}}$ 36, p. 220.

${ }^{43}$ DÍEZ RIPOLLÉS, “Exigencias sociales”, cit. nota n⿳2 25, p. 49.

${ }^{44}$ DÍEZ RIPOLLÉS, J.L., "De la sociedad del riesgo a la seguridad ciudadana: un debate desenfocado", en: Homenaje al profesor Dr. Gonzalo Rodríguez Mourullo, Madrid: Civitas, 2005, pp. 267-305.
} 
MARQUÈS I BANQUÉ, Maria. "Problemas de legitimación del Derecho penal del miedo".

Ante lo que en algún momento se ha interpretado como un síntoma de desprecio recíproco entre pensamiento científico y ciudadanía, la doctrina advierte de la necesidad de no construir un discurso académico hermético a los problemas reales (riesgo que se corre de prescindir sistemáticamente de lo que los ciudadanos sienten y piensan), sin que ello signifique, como señala Gonzalo Quintero Olivares, "justificar la grosera invocación de la 'práctica' y de la opinión 'popular' (que por lo general se identifica con la de algunos medios de comunicación) en torno a la realidad de los problemas jurídicos y el mejor modo de superarlos" $" 45$.

En otro orden de consideraciones, cabe todavía añadir que la instrumentalización política del Derecho penal no debe confundirse con la "politización interna" del mismo, fenómeno descrito por Wolfgang Naucke en 1987 y señalado frecuentemente por los autores que abordaron el problema del Derecho penal del riesgo ${ }^{46}$. A partir del análisis y comparación de la evolución política de una parte y de la legislación y teoría penales de otra durante los siglos diecinueve y veinte en Alemania, Naucke establece la estrecha relación existente entre Derecho penal y política llegando a la conclusión de que siguen caminos paralelos correspondiendo a la política la función de guiar este común avanzar y no a la inversa. Para ello, no hay que entender el concepto de política en sentido abstracto sino en su dimensión concreta, como política interna de un Estado determinado en un momento dado. Política interna se identifica, en este sentido, con política de partidos, configurándose el Derecho penal como producto resultante de ella ${ }^{47}$. El interés de Naucke cuando describe un Derecho penal politizado es precisamente establecer el sentido en que se produce la influencia: de la política al Derecho penal. De ahí que considere erróneas aquellas aproximaciones teóricas a la relación Derecho penal-política basadas en una voluntad de 'cientificación' de la política, entendida como el traslado a la legislación penal de aquellas teorías penales que gozan de aprobación doctrinal (o más exactamente, de aquel sector de la doctrina con incidencia puntual sobre la elaboración de las reformas penales) prescindiendo del proceso y el contexto político en que se inserta todo acto legislativo. En opinión de Naucke, el deber del penalista es precisamente señalar la politización interna del Derecho penal como fenómeno tendencialmente negativo y buscar propuestas alternativas dotadas de suficiente autonomía respecto de políticas partidistas.

\footnotetext{
${ }^{45}$ QUINTERO OLIVARES, G., "La deriva y crisis de las ideas penales en España", en: OCTAVIO DE TOLEDO Y UBIETO, E.; GURDIEL SIERRA, M.; CORTÉS BECHIARELLI, E. (Coords.), Estudios Penales en recuerdo del profesor Ruiz Antón, Valencia: Tirant lo Blanch, 2004, p. 933. Recuerda este autor que ya antes en Alemania, fue HASSEMER quien hizo esta advertencia a propósito del problema del contenido de la culpabilidad.

${ }^{46}$ NAUCKE, W., "Entwicklungen der allgemeinen Politik und der Zusammenhang dieser Politik mit der Reform der Strafrechts in der Bundesrepublik Deutschland", en: HASSEMER, W. (Ed.), Strafrechtspolitik, Frankfurt am Main: Peter Lang, 1987, pp.15-32. Véase asimismo HERZOG, "Límites", cit. nota n 34, p. 321 y ss..

${ }^{47}$ Según este autor, no es el modelo de Estado el que condiciona un determinado Derecho penal, sino la política del partido que ostenta el Gobierno (o la política de consenso en caso de Gobiernos de coalición). En este sentido, NAUCKE niega la capacidad del modelo constitucional en sí mismo para determinar un específico sistema penal, sin perjuicio de las consecuencias que para su construcción puedan y deban derivarse de la Constitución. Paradigmático resulta en este sentido para este autor el Derecho penal de la etapa nacionalsocialista a pesar de la existencia formal de una Constitución (NAUCKE, "Entwicklungen", cit. nota $\mathrm{n}^{\circ} 46$, p. 21 y ss.).
} 
La noción de Derecho penal politizado, por tanto, contribuye a la descripción de la naturaleza de las relaciones entre Derecho penal y política sin que constituya tampoco un fenómeno específico de la sociedad del riesgo. Es más, como recuerda Quintero Olivares, la propia historia penal española es exponente del estrecho vínculo existente entre los cambios de régimen político y los cambios legales penales. La plasmación de los distintos vaivenes políticos en el derecho penal positivo, con el fin de acomodar sus normas al marco social y político en que deben aplicarse, es por lo demás considerado por este autor como "perfectamente coherente, pues el derecho penal es la parcela del sistema jurídico que más directamente incide, junto al orden constitucional, en los derechos e intereses fundamentales de los ciudadanos" ${ }^{\prime \prime}$.

Sin embargo, en la sociedad del riesgo, dadas las excesivas exigencias de intervención y la presión sufrida a consecuencia de ello por el legislador, la politización interna del Derecho penal favorece su instrumentalización política. El innegable vínculo entre Derecho penal y política de partidos se torna en el Derecho penal del miedo en supeditación a los intereses de partido, los cuales, tal y como ya he apuntado, giran en demasiadas ocasiones en torno a la idea de mantenimiento del poder. Ello permite compartir con Naucke la consideración de la politización interna del Derecho penal como fenómeno "tendencialmente negativo" a pesar de ser conceptualmente "perfectamente coherente" en el sentido expresado por Quintero Olivares.

\section{La funcionalización ilegítima del Derecho penal}

Quiero comenzar este apartado fijando mi opinión sobre el tema que se enuncia, y este es que la orientación a la seguridad subjetiva, característica en los sistemas normativos de la llamada sociedad del riesgo, genera en el Derecho penal una vulneración del principio de exclusiva protección de bienes jurídicos, que se supone central, y por lo mismo da lugar a una funcionalización ilegítima del mismo. Lo importante, según creo, es que la orientación a la seguridad abre la puerta a la perversión de las funciones y fines del Derecho penal. Seguidamente abordaré la idea de funcionalización, pues es patente que no es entendida de manera unívoca.

Señalaba más arriba que la instrumentalización política del Derecho penal que resulta de la orientación a la seguridad subjetiva ha sido señalada como una forma de funcionalización ilegítima del mismo. Establecido el contenido de las relaciones que entiendo legítimas entre Derecho penal y política y asentado a partir de ello el concepto de instrumentalización política, debe de determinarse a continuación en qué medida cabe entender dicha instrumentalización como una "funcionalización ilegítima del Derecho penal” y hasta qué

\footnotetext{
${ }^{48}$ QUINTERO OLIVARES, G.; MUÑOZ CONDE, F., La reforma penal de 1983, Barcelona: Ediciones Destino,1983, pp. 13-14, y especialmente, en QUINTERO OLIVARES, G., Adonde va el Derecho Penal. Reflexiones sobre las Leyes Penales y los penalistas españoles, Madrid: Thomson Civitas, 2004, passim. Sobre el tema, ya mucho antes BARBERO SANTOS, M., Política y Derecho penal en España, Madrid: Tucar, 1977. Otro ejemplo de las relaciones entre Derecho penal y política, esta vez desde la perspectiva de las teorías de la pena, en CUERDA RIEZU, A., El legislador y el Derecho penal (una orientación a los orígenes), Madrid: Editorial Centro de Estudios Ramon Areces, 1991, pp. 15-42.
} 
MARQUÈS I BANQUÉ, Maria. "Problemas de legitimación del Derecho penal del miedo".

punto puede considerarse una característica del Derecho penal del miedo, siendo preciso, ante todo, realizar algunas puntualizaciones de carácter terminológico.

Establecer el significado de la expresión "funcionalización del Derecho penal" requiere, en primer lugar y por más que parezca obvio, delimitar el concepto de otras formas de funcionalización igualmente dables en el seno de la teoría penal y que describen fenómenos distintos a él si bien en ocasiones coincidentes en una misma construcción doctrinal. Me refiero, como es sabido, a cuestiones como la relativa a la funcionalización de la dogmática, las corrientes funcionalistas o la funcionalización del bien jurídico dentro de la teoría del bien jurídico ${ }^{49}$. Al abordar el tema de la funcionalización me limitaré a la que se predica del Derecho penal, entendiéndola como la orientación del sistema penal a determinados objetivos o principios: la construcción del Derecho penal en función de algo concreto, de aquello que se pretende a través de su actuación.

La atribución de un objetivo específico al Derecho penal al cual éste debe orientarse (o funcionalizarse) lleva al ámbito de la llamada función del Derecho penal, o en plural y lo que es distinto, a las señaladas funciones del Derecho penal. En el primer caso, cuando se habla de función del Derecho penal en singular, suele hacerse referencia a lo que algunos autores han considerado más correcto denominar fin del Derecho penal como concepto equivalente a misión, a aquello que se espera de él, a la consecuencia perseguida con la intervención punitiva. El fin del Derecho penal pertenece, por tanto, al ámbito del "deber ser". En cambio, cuando se alude a las funciones del Derecho penal en plural, se hace referencia a aquellos "efectos sociales empíricos del Derecho penal, que han de quedar fuera de toda teoría de legitimación del mismo" ".50. Estamos, por consiguiente, en el ámbito del "ser", de aquello que efectivamente puede identificarse como consecuencia real del Derecho penal aunque no se previera o deseara en un principio. Siguiendo a Luigi Ferrajoli, mientras la palabra "fin" indica los usos normativos, la palabra "función" indica los usos descriptivos de la pena ${ }^{51}$.

En este sentido, es conveniente advertir que hasta aquí se ha aludido en ocasiones a la función del Derecho penal en el sentido expuesto de fin o misión, sin que ello suponga nada

\footnotetext{
${ }^{49}$ Afirma SILVA SÁNCHEZ: "una cosa es la concepción funcional o teleológica de la dogmática y otra, no necesariamente coincidente con la anterior en un mismo cuerpo doctrinal, la fundamentación utilitarista del Derecho penal", a lo que añade en pie de página: "ello, independientemente de que con frecuencia puedan coincidir la concepción funcional del sistema de la teoría del delito y la concepción utilitarista acerca de la legitimación del Derecho penal" (SILVA SÁNCHEZ, J.M., Aproximación al Derecho penal contemporáneo, Barcelona: J.M. Bosch Editor, 1992, p. 72).

${ }^{50}$ SILVA SÁNCHEZ, Aproximación, cit. nota no 49, p. 299. Este autor, si bien adopta la terminología apuntada como más correcta, señala que los autores que la propugnan "reconocen que en el lenguaje jurídico tradicional el término función alude a las consecuencias queridas de una cosa" (p. 299, nota al pie de página núm. 486). HASSEMER y MUÑOZ CONDE, a quienes debe atribuirse la afirmación recogida por SILVA, optaron por el lenguaje sociológico, en el que por función se entiende, en cambio, "la suma de las consecuencias objetivas de una cosa", debiendo de ser empleado este término para desginar "las consecuencias (accesorias) no deseadas pero reales del sistema" (HASSEMER, W.; MUÑOZ CONDE, F., Introducción a la Criminología y al Derecho penal, Valencia: Tirant lo Blanch, 1989, p. 99).

${ }^{51}$ FERRAJOLI, L., "El derecho penal mínimo" (trad. de R. Bergalli), Poder y Control núm. 0 (1986), p. 26. A partir de dicha distinción, llama este autor las teorías relativas a los fines "teorías axiológicas o de justificación", y las teorías relativas a los usos descriptivos "teorías explicativas o explicaciones". Véase asimismo FERRAJOLI, Diritto e ragione, cit. nota n ${ }^{\circ}$ 40, p. 314 y ss.
} 
más que una preferencia terminológica, orientada a una mejor comprensión del concepto de funcionalización. Es precisamente la distinción conceptual entre fines y funciones lo que me permitirá calificar de ilegítimas determinadas formas de funcionalización del Derecho penal. Así, se pretende llegar a la conclusión de que una de estas formas ilegítimas de funcionalización es la elevación de funciones reales del Derecho penal a la categoría de fines del mismo y que ello representa una de las características principales del Derecho penal del miedo y, en cuanto a presupuesto del mismo, uno de sus rasgos más discutidos desde la óptica del Derecho penal liberal. En este sentido, tendremos ocasión de ver cómo en el seno del Derecho penal del miedo se incurre en el "vicio metodológico" denunciado por Ferrajoli (cuando de contestar a la pregunta "por qué se castiga" se trata) consistente en la confusión "entre función y fin, o bien entre el ser y el deber ser de la pena, y en la consecuente asunción de las explicaciones como justificaciones o viceversa" ${ }^{2}$. Concretamente, veremos cómo el Derecho penal del miedo es expresión de la llamada falacia naturalista, la cual supone la comprensión de las teorías sociológicas (explicativas) como doctrinas de justificación o, lo que es lo mismo, la derivación del deber ser a partir del ser ${ }^{53}$.

Entiendo pues, que por funcionalización del Derecho penal cabe hacer simplemente referencia a la atribución de objetivos específicos al Derecho penal, sin que ello conlleve, en principio, ninguna carga valorativa de sentido negativo. No obstante, no siempre es entendido así. Es más, cuando de "funcionalización del Derecho penal" se habla, existe una tendencia general a atribuir un determinado significado a la expresión. En este sentido, ya advierte Cornelius Prittwitz que "si bien la expresión 'funcionalización del Derecho penal' suele ser empleada de forma negativa para designar su abuso, tal valoración es cualquier cosa menos evidente" 54 . En efecto, ello supone atribuirle un contenido unívoco al término siendo precisas algunas consideraciones antes de poder valorar el fenómeno en un determinado sentido. Ejemplo de los diversos contenidos a los que puede hacer referencia la expresión es, para este autor, la opinión de Hassemer, según la cual, característica del Derecho penal moderno es - precisamente- la funcionalización de los principios penales a las exigencias de una política criminal efectiva ${ }^{55}$. La funcionalización del Derecho penal entendida en este caso como expresión del fenómeno por el cual "la orientación a las consecuencias, que en el Derecho penal clásico sólo era un criterio adicional para justificar una adecuada legislación, se convierte en objetivo predominante del Derecho penal

\footnotetext{
${ }^{52}$ FERRAJOLI, "El derecho penal mínimo", cit. nota no 51, p. 26. Cabe precisar que la expresión utilizada por el autor en Diritto e ragione es la de "defecto epistemológico" o "vicio ideológico" (FERRAJOLI, Diritto e ragione, cit. nota $\mathrm{n}^{\circ} 40$, pp. 318 y 319 ).

53 Junto a la "falacia naturalista" se habla de la "falacia normativista" para describir el vicio en el que incurren aquellas doctrinas normativas de la pena que confunden asimismo fines y funciones (llamadas por ello ideologías normativistas o idealistas) asumiendo como descriptivo lo que no es más que un modelo normativo (explicación del ser a partir del deber ser). Sobre estos conceptos FERRAJOLI, "El derecho penal mínimo", cit. nota $\mathrm{n}^{\circ}$ 51, p. 27; y FERRAJOLI, Diritto e ragione, cit. nota n $^{\circ}$ 40, pp. 316 y 317.

${ }^{54}$ PRITTWITZ, "Funktionalisierung", cit. nota n' 17, p. 435.

55 PRITTWITZ, "Funktionalisierung", cit. nota $\mathrm{n}^{\circ}$ 17, p. 435. A su vez, la opinión de HASSEMER y su desarrollo crítico puede consultarse en "Lineamientos de una teoría personal del bien jurídico" (trad. de Patricia S. Ziffer), Doctrina Penal año 12, n 45 a 48 (1989), pp. 275-285, así como en "Rasgos y crisis del Derecho penal moderno" (trad. de Elena Larrauri), Anuario de Derecho Penal y Ciencias Penales Vol. 45, N ${ }^{\circ}$ 1 (1992), pp. 239-249.
} 
MARQUÈS I BANQUÉ, Maria. "Problemas de legitimación del Derecho penal del miedo".

moderno" 56 , no supone a priori ningún abuso o desviación del mismo sino que se limita a describir uno de los rasgos del Derecho penal moderno que, en cuanto a tal, puede ser posteriormente objeto de alabanza o crítica según la opción doctrinal que se tome.

En realidad y en opinión de Prittwitz, la primera pregunta que todo penalista debería formularse es si acepta o no la existencia de una función a cumplir por el Derecho penal. En la medida en que la respuesta sea afirmativa, como por otra parte lo es por lógica en la doctrina si se prescinde del contenido concreto de dicha función y con la única excepción de las teorías abolicionistas ${ }^{57}$, deberemos admitir una determinada funcionalización del Derecho penal: aquélla que nosotros mismos le asignemos. Es el establecimiento de esta premisa, lo que permite al citado autor establecer una frontera entre formas legítimas e ilegítimas de funcionalización ${ }^{58}$. Desde luego, y no por obvio debe dejar de apuntarse, entiendo que toda valoración de legitimidad deberá alejarse de pretensiones de validez absoluta, desde el momento en que la "legitimidad" se configura como un concepto relativo en tanto que dependiente de la personal opción doctrinal que se tome acerca de la función que cabe predicar del Derecho penal. Ilegítima será, en este sentido, toda atribución de funciones al Derecho penal distintas de aquella que se predica como válida desde una determinada opción teórica.

A partir de ahí, y desde la opción doctrinal de la que parto, puede afirmarse que el Derecho penal se encuentra funcionalizado a la protección de bienes jurídicos, por entender ésta como su única y legítima función ${ }^{59}$. En este sentido, toda desviación o vulneración del principio de exclusiva protección de bienes jurídicos que suponga la atribución, encubierta o no, de otra misión distinta al Derecho penal, deberá ser considerada como una forma de funcionalización ilegítima del mismo.

Me interesa a continuación, ver en qué medida la orientación a la seguridad subjetiva propia del Derecho penal del miedo supone una funcionalización ilegítima del Derecho penal a partir de la vulneración del principio de protección de bienes jurídicos.

\footnotetext{
${ }^{56}$ HASSEMER, "Rasgos", cit. nota no 55, p. 239. Véase asimismo una descripción del fenómeno de la funcionalización en HASSEMER/MUÑOZ CONDE, Introducción, cit. nota $n^{\circ}$ 50, p. 173). En relación con la crisis de la orientación a las consecuencias y su relación con el concepto de funcionalización aquí defendido, véase más adelante, a propósito del Derecho penal simbólico.

${ }^{57}$ Cabe matizar que el discurso de las teorías abolicionistas suele girar en torno a la supresión del Derecho penal como consecuencia de la no verificación empírica de sus fines normativos, de la existencia teórica de los cuales, por tanto, se parte necesariamente. La negación de una función o misión a cumplir por el Derecho penal (en definitiva, su abolición) será fruto del contraste entre dicha misión y el grado de insatisfacción de la misma. En relación con este discurso argumentativo de muchas de las teorías abolicionistas, véanse las particularmente interesantes observaciones de Ferrajoli, quien considera que aquellas incurren en el mismo "vicio metodológico" que muchas doctrinas de justificación de la pena. En opinión de este autor, toda doctrina abolicionista que pretenda ser "consistente" y no convertirse en una ideología, no debería reparar tanto en la "insatisfacción" como en la "imposibilidad de satisfacer" (FERRAJOLI, "El derecho penal mínimo", cit. nota n ${ }^{\circ}$ 51, pp.28 a 31. Asimismo FERRAJOLI, Diritto e ragione, cit. nota no 40, p. 322).

${ }^{58}$ PRITTWITZ, "Funktionalisierung", cit. nota $\mathrm{n}^{\circ} 17$, p. 436. Hay que precisar, no obstante, que este autor abordaba la cuestión de la función del Derecho penal y la correspondiente funcionalización ilegítima del mismo desde las teorías de la pena.

59 Afirmación que no contradice el reconocimiento de las llamadas "funciones latentes" del Derecho penal si bien sólo se aceptan como tales. Véase sobre ello más adelante a propósito del Derecho penal simbólico.
} 
Es notorio, que la relación entre Derecho penal y política encuentra una de sus manifestaciones más palmarias en la construcción del catálogo de bienes jurídicos protegidos de cada momento histórico y político. De ahí que sea también uno de los primeros ámbitos en sufrir las consecuencias de la instrumentalización política y la funcionalización del Derecho penal, fenómenos que, como afirmaba más arriba, repercuten directamente sobre la operatividad de los principios informadores y límites del ius puniendi, con lo que ello representa para la tradición jurídica liberal.

Ejemplo clásico de transgresión del principio de exclusiva protección de bienes jurídicos es el uso del Derecho penal como instrumento para la imposición de valores morales no mayoritarios en una sociedad democrática, siendo conocido el rechazo unánime que tal posibilidad suscitó tiempo atrás en la doctrina ${ }^{60}$. Sin embargo, cabe preguntarse si no hay otras formas más encubiertas de transgresión de este principio que la anteriormente descrita y si la orientación a la seguridad subjetiva no es una de ellas.

La primera de las cuestiones, la relativa a la existencia de formas más encubiertas de transgresión, debe ser contestada en sentido afirmativo a tenor de las observaciones doctrinales que han advertido de la alteración que para la función limitadora del bien jurídico - cuya garantía reside esencialmente en la naturaleza extrasistemática del concepto, supone la consideración del sistema punitivo vigente como criterio de referencia para las decisiones de criminalización o descriminalización de conductas. En este sentido puede interpretarse la opinión de Hassemer, para quien constituye "un cambio de forma subrepticia" del principio de protección de bienes jurídicos su transformación de un principio negativo a uno positivo de criminalización ${ }^{61}$. El bien jurídico pierde de esta manera su condición de filtro ineludible del instrumento punitivo para pasar a constituir un argumento de justificación de la intervención penal (entendida como creación de nuevos tipos o como mantenimiento o agravación de los existentes) en el que poder ampararse a la hora de defender una determinada opción política ${ }^{62}$.

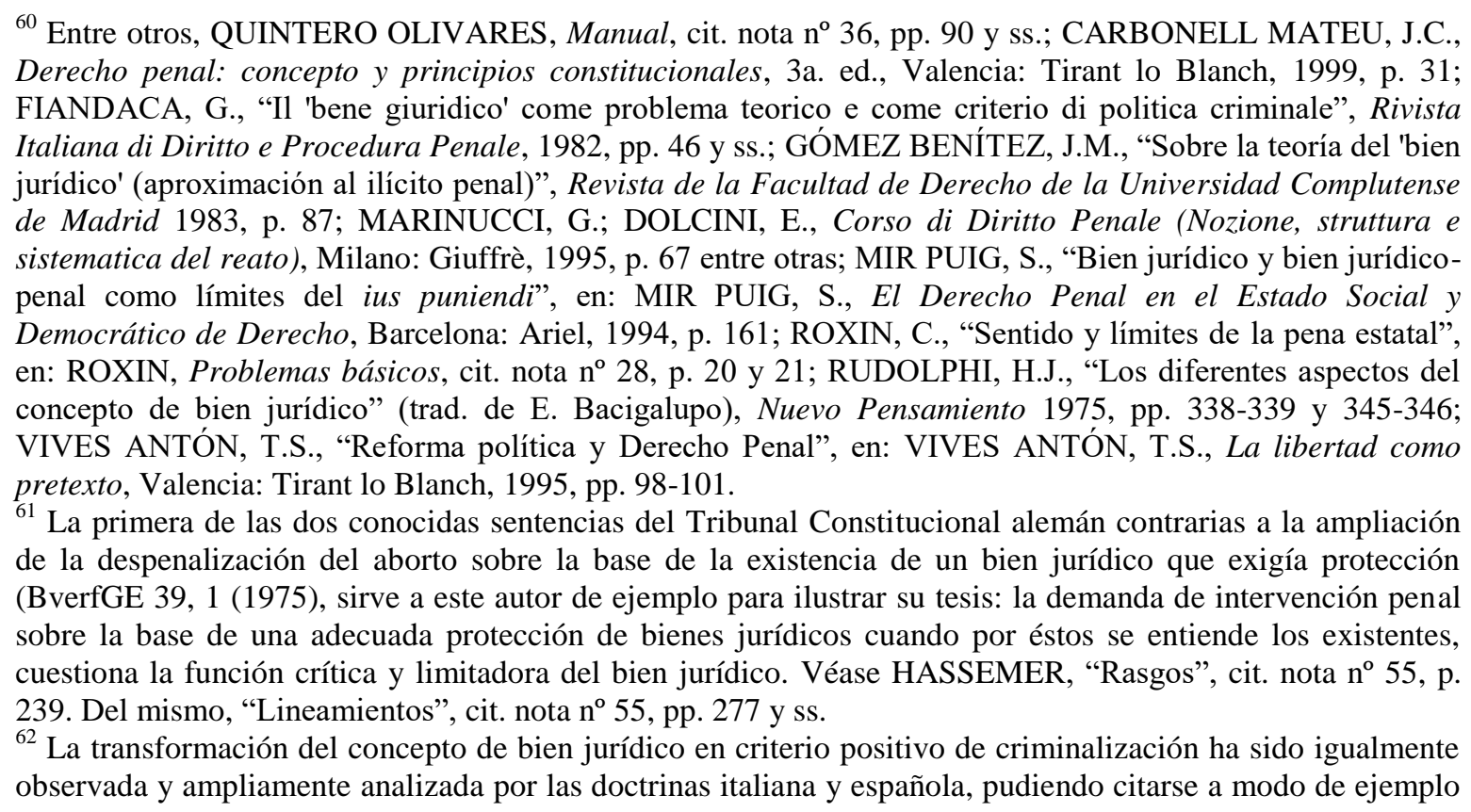


MARQUÈS I BANQUÉ, Maria. "Problemas de legitimación del Derecho penal del miedo".

En opinión de Fermín Morales Prats, este 'giro copernicano' del papel teleológico asignado al bien jurídico, "encuentra su explicación en la teorización más o menos explícita de funciones promocionales o propulsivas en el Derecho penal y, en particular, en la fijación de obligaciones de tutela penal a partir de los principios programáticos de la Constitución de contenido social" ${ }^{\prime 63}$.

Por su relación con ideas ya expresadas más arriba, quisiera señalar que la pérdida de la función limitadora del bien jurídico derivada de una selección de bienes jurídicos $-\mathrm{y}$, por tanto, de la elaboración de criterios de intervención- desde dentro del mismo sistema, puede considerarse una manifestación del fenómeno de politización interna del Derecho penal descrito por Naucke y, por tanto, terreno de abono para su instrumentalización política. Cobran así actualidad los temores expresados por la doctrina en los años ochenta del siglo XX cuando se señalaba cómo detrás de la función limitadora del bien jurídico no había sino un problema de desconfianza en el legislador ordinario. La búsqueda de límites a la intervención penal expresaba ya entonces la preocupación por un uso interesado del instrumento penal "para la consecución de fines parciales"64.

Sin embargo, la consideración de la orientación a la seguridad subjetiva característica del Derecho penal del miedo como forma de vulneración del principio de protección de bienes jurídicos, no coincide con el fenómeno señalado por Hassemer. La vulneración indicada por este autor, si bien afecta a una de las funciones principales del bien jurídico, cual es la limitadora, no supone por ello la atribución de una función al Derecho penal distinta a la de protección de bienes jurídicos $\mathrm{y}$, por tanto, no supone una forma de funcionalización ilegítima del Derecho penal en el sentido más arriba indicado. Misión del Derecho penal sigue siendo la protección de bienes jurídicos, si bien el proceso de configuración de los mismos pierde uno de sus más importantes filtros críticos prestándose con ello a ser objeto de politización interna. Se trata, por lo demás, de una forma de vulneración del principio de protección de bienes jurídicos que si bien puede darse en una sociedad del riesgo no puede decirse que sea exclusiva o tan siquiera característica de ella.

una afirmación de PULITANÒ que hizo cierta fortuna, a tenor de la cual "de la necesidad de que la tutela penal se oriente a objetos idóneos, se ha pasado a afirmar la necesidad de que se proporcione tutela penal a todo objeto idóneo" (PULITANÒ, D., "La teoria del bene giuridico fra codice e costituzione", La Questione Criminale 7 (1981), pp. 114).

${ }^{63}$ MORALES PRATS, F., "Funciones del Derecho penal y sociedad civil”, en: CANESTRARI, S. (Ed.), Il Diritto penale alla svolta di fine millenio (Atti del Convegno in ricordo di Franco Bricola, Bologna 18-20 maggio 1995), Torino: Giappichelli Editore, 1998, p. 62. Por su parte, MUÑOZ CONDE vincula los cambios observados en el papel del bien jurídico y el principio de intervención mínima a los nuevos problemas planteados por la sociedad moderna cuya naturaleza lleva a "que en esta materia el nuevo Código Penal tenga una mayor vocación penalizadora que despenalizadora y que conciba el Derecho Penal más como un instrumento político de dirección social que como un mecanismo de protección subsidiaria de las otras ramas del ordenamiento jurídico" (MUÑOZ CONDE, F., "Protección de los derechos fundamentales en el Código Penal", en: VV.AA., Estudios sobre el Código Penal de 1995 (Parte General), Madrid: CGPJ 1996, p. 447. Publicado también en Derecho y Cambio Social, Año 7, № 22 (2011)).

${ }^{64}$ En estos término se expresaba GONZÁLEZ RUS, J.J., Bien jurídico y Constitución (Bases para una teoría), Madrid: Fundación Juan March, 1983, p. 29, quien señalaba cómo los excesos de la etapa política anterior habían puesto de manifiesto la necesidad de recuperar y reformular a la luz de la Constitución de 1978 el concepto liberal de bien jurídico. 
Confirmo con ello mi opinión, al principio expuesta: la orientación a la seguridad subjetiva que se ha descrito como típica del conjunto normativo de una sociedad del riesgo, sí supone en el ámbito del Derecho penal una vulneración del principio de exclusiva protección de bienes jurídicos que conlleva una funcionalización ilegítima del mismo. Y en la medida en que dicha nueva orientación encuentra sus razones en los intereses más inminentes de la clase política, se evidencia su estrecha relación con los fenómenos de politización interna e instrumentalización política del Derecho penal, los cuales, tal y como ya se advertía más arriba, si bien tampoco son privativos del Derecho penal del miedo, sí se ven potenciados en su contexto. Veámoslo a continuación con más detalle.

Punto de partida para la comprensión del Derecho penal del miedo ha sido el establecimiento de la orientación a la seguridad subjetiva como uno de sus presupuestos esenciales. Las excesivas e intensas demandas de intervención estatal por parte de la población en aras a mitigar la sensación de inseguridad derivada del conjunto de riesgos por los que se siente amenazada, han supuesto, como se indicaba más arriba, el detonante del uso y abuso del Derecho penal como instrumento de resolución de conflictos sociales más allá de lo que aconsejaría una intervención debidamente informada por los principios limitadores del ius puniendi, y en especial, por los principios de subsidiariedad, intervención mínima, fragmentariedad y ultima ratio. Todo ello, además, con la agravante de que los conflictos sociales que se consigue resolver son únicamente, como se verá más adelante de modo más detallado a propósito de la llamada legislación simbólica, los de carácter psíquico (la inseguridad subjetiva, el miedo de la ciudadanía) sin que sea necesariamente abordado el efectivo control de esas fuentes de riesgo generadoras de tanta angustia colectiva. No obstante, en la medida en que es el equilibrio psicológico lo que parece garantizar la confianza en el Estado y no el tratamiento real de los procesos de riesgo a través de políticas preventivas adecuadas que podrían pasar desapercibidas por la mayoría de la ciudadanía, el legislador no sólo no reacciona en contra de ello sino que potencia dicha forma de instrumentalización política del Derecho penal.

Nos encontramos, por tanto, ante un Derecho penal cuya misión se convierte en la consecución de la seguridad subjetiva en tanto que necesaria para la satisfacción de intereses políticos. La protección de bienes jurídicos queda, de esta manera, relegada a un segundo plano como fin "formal" del Derecho penal, pues no siempre se admite de forma manifiesta el trueque de funciones que supone reorientar el Derecho penal a estas nuevas finalidades. Nótese que función encubierta del Derecho penal pasa a ser la seguridad subjetiva pero sólo en tanto que ésta posibilita, a su vez, la consecución de determinadas finalidades políticas. De ahí, que pueda considerarse la instrumentalización política como una forma de funcionalización ilegítima del Derecho penal: a partir de su consideración como instrumento idóneo para la obtención de los beneficios que puede aportar al Estado la convicción colectiva de resolución de los problemas sociales, se orienta el Derecho penal a la seguridad subjetiva. Y establecer la seguridad subjetiva como nuevo fin del Derecho penal distinto al de protección de bienes jurídicos es, en los términos aludidos en estas páginas, proceder a una forma de funcionalización ilegítima del mismo. Desde luego, cabría preguntarse si la seguridad subjetiva no puede ser considerada en sí misma como un bien jurídico, pero ésta es una cuestión distinta que, por su interés y complejidad, debería ser objeto de un detenido análisis en otro lugar. 
MARQUÈS I BANQUÉ, Maria. "Problemas de legitimación del Derecho penal del miedo".

Apuntaba además, que la funcionalización ilegítima que se predica del Derecho penal del miedo supone una elevación de funciones reales del Derecho penal a la categoría de fines del mismo. En efecto, cuando se señalan las funciones que cumple el Derecho penal a nivel descriptivo entendidas como aquellas consecuencias reales no previstas o queridas del mismo, se alude por la doctrina a la "función de satisfacción de necesidades de psicología social" 65 , las cuales podrían definirse como aquellas sentidas por la colectividad a nivel íntimo o subjetivo y que pueden verse satisfechas a través del castigo.

Ejemplo paradigmático de necesidad de psicología social es precisamente la seguridad subjetiva, cuya satisfacción, sin embargo, no debería entenderse limitada al Derecho penal. Un tratamiento técnico o normativo adecuado de las fuentes de riesgo desde otras ramas del Derecho, puede estabilizar psicológicamente la sociedad en la medida en que ésta así lo perciba. En tanto que forma normativa de prevención, también un Derecho penal orientado a la protección de bienes jurídicos respetuoso con los criterios de fundamentación y limitación de la intervención, podría tener el mismo efecto beneficioso sobre la colectividad.

El problema surge cuando a partir de las inercias e intereses del legislador se hace creer a la sociedad que el único sistema efectivo de control de riesgos es el instrumento punitivo, terminando por condicionar la consecución de la seguridad subjetiva al siempre llamativo uso del Derecho penal. Se entra con ello en un círculo vicioso de difícil solución: a partir del momento en que el legislador descubre lo "fácil" que le resulta el recurso a un instrumento como el Derecho penal cuyas ventajas en el ámbito político se demuestran a partir de la función real de satisfacción de la necesidad social de seguridad subjetiva que cumple, la intervención punitiva se intensifica. Y con la intensificación de la intervención punitiva, se genera todavía más la sensación colectiva del Derecho penal como medio idóneo (puede decirse incluso que único) para la resolución de los problemas sociales (el control de las fuentes de riesgo en este caso) generando con ello una mayor demanda de intervención, lo que termina por dificultar, si no imposibilitar, la operatividad de aquellos principios que debían garantizar la contención penal. Puesto que la vuelta atrás aparece como demasiado costosa a la clase política, se termina por funcionalizar el Derecho penal a la satisfacción de una mera necesidad de psicología social, cual es la seguridad subjetiva, transformando lo que se había demostrado como una función real del Derecho penal, en su fin o misión ${ }^{66}$.

Ante la cuestión de si puede admitirse que realmente sean las necesidades de psicología social las que rijan la intervención penal, Jesús María Silva Sánchez señala que "una concepción legitimadora de la intervención penal no puede permitir que ésta se vea regida por las tendencias irracionales, subconscientes, de la sociedad, que se manifiestan en una determinada configuración de las necesidades de pena" ${ }^{\natural 7}$. A esto cabría añadir las críticas

\footnotetext{
${ }^{65}$ SILVA SÁNCHEZ, Aproximación, cit. nota no 49, pp. 307 y 308.

${ }^{66}$ En este sentido HERZOG, Gesellschaftliche, cit. nota n ${ }^{\circ} 17$, p. 50, quien hablaba del traslado de "funciones latentes del Derecho penal al plano normativo" como forma de funcionalización.

67 SILVA SÁNCHEZ, Aproximación, cit. nota n 49, p. 307. En el mismo sentido de rechazar que "el apaciguamiento de los sentimientos de inseguridad pueda constituir objetivo en sí mismo del Derecho penal", se ha manifestado ampliamente la doctrina en los últimos años. En estos exactos términos, por ejemplo, DÍEZ
} 
que puede suscitar la participación del legislador en el desarrollo de este fenómeno, máxime si tenemos en cuenta que "el abuso de los instintos humanos por parte de la demagogia política se encuentra, desde antiguo, entre las técnicas propias de un ejercicio

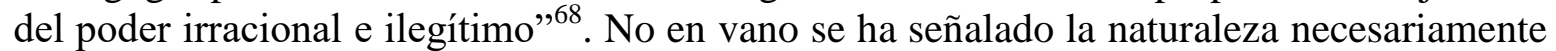
"atormentada" de la relación entre la ciencia penal y la política, pues ninguna rama del Derecho tiene tanto que ver con la irracionalidad como el Derecho penal, cuya tarea es la de disciplinar comportamientos irracionales y prevenir reacciones irracionales ${ }^{69}$.

A partir de las anteriores consideraciones, puede formularse ya una conclusión: efectivamente, la orientación a la seguridad subjetiva que caracteriza el Derecho penal del miedo y la instrumentalización política que se deriva de la misma, suponen una funcionalización ilegítima del mismo en cuanto vulneración, en ocasiones encubierta, del principio de protección de bienes jurídicos.

De todo lo anterior, sin embargo, surgen todavía algunas cuestiones susceptibles de consideración. Por una parte, cabe preguntarse si de ello se deriva que toda transgresión del principio de exclusiva protección de bienes jurídicos supone una funcionalización ilegítima del Derecho penal y, por otra, si instrumentalización política y funcionalización son siempre fenómenos coincidentes de forma que el primero conduzca necesariamente al segundo o viceversa.

En relación con la primera de las cuestiones y a tenor de los ejemplos que acabo de exponer (la protección de valores meramente morales, la pérdida de la función limitadora del bien jurídico señalada por Hassemer y la transgresión que supone orientar el Derecho penal a la seguridad subjetiva), parece que para poder hablar de funcionalización del Derecho penal se requiera un plus: que la vulneración afecte a la misma protección de bienes jurídicos en cuanto a misión del Derecho penal. Se trataría de desplazarla y sustituirla por otra función. Sin embargo, entiendo que un planteamiento tan lineal podría pecar de ingenuidad por varias razones. En primer lugar, porque la mayoría de las veces dicho desplazamiento se producirá, como se ha tenido ocasión de ver, de forma encubierta, postulándose todavía la protección de bienes jurídicos como misión de un Derecho penal orientado en realidad a nuevos objetivos y finalidades de carácter esencialmente político. En segundo lugar, y lo que me parece más importante, porque la línea divisoria entre aquellas transgresiones que afectan a un aspecto determinado del principio de protección de bienes jurídicos sin que ello altere su validez en cuanto a indicador de la función del Derecho penal, y aquellas transgresiones que supongan una desviación esencial del mismo privándole de toda operatividad real, me parece, a priori, como de difícil delimitación.

RIPOLLÉS, J.L., "La víctima del delito en la política criminal y el derecho penal", Jueces para la Democracia núm. 57 (2006), p. 33.

${ }^{68}$ PRITTWITZ, C., "La concorrenza diseguale tra sicurezza e libertà", en: DONINI, M.; PAVARINI, M. (Eds.), Sicurezza e Diritto Penale, Bologna: Bononia University Press, 2011, p. 116.

${ }^{69}$ DONINI, M., "La relación entre Derecho penal y política: método democrático y método científico" (trad. de C. Méndez Rodríguez), en: ARROYO ZAPATERO, L.; NEUMANN, U.; NIETO MARTÍN, A. (Coords.), Crítica y Justificación del Derecho Penal en el cambio de siglo, Cuenca: Ediciones de la Universidad de Castilla-La Mancha, 2003, p. 71. 
MARQUÈS I BANQUÉ, Maria. "Problemas de legitimación del Derecho penal del miedo".

Más allá de lo que se dice o no proteger -lo que supondría atender a un criterio formal que se ha demostrado como de escasa fiabilidad- lo decisivo en aras a diagnosticar una funcionalización ilegítima del Derecho penal, sería diferenciar entre aquellas orientaciones puntuales a objetivos alejados del bien jurídico pero en el contexto de un sistema penal esencialmente respetuoso con los principios y garantías liberales (lo que podría predicarse de determinados actos legislativos o incluso aplicativos, y ser considerado en su caso sólo como concretas expresiones del criticable fenómeno de instrumentalización política), y aquella reorientación del conjunto de la intervención punitiva que implica una transformación de la misión del Derecho penal y, en consecuencia, la relajación o abandono de los principios propios de la tradición jurídico-liberal. Un Derecho penal ilegítimamente funcionalizado como lo es el Derecho penal del miedo, sería, por tanto, algo más que un Derecho penal con determinadas manifestaciones legislativas cuestionables desde el punto de vista del principio de exclusiva protección de bienes jurídicos. Se trataría de la concepción de un sistema penal nuevo, cuya transformación operada en los presupuestos no se agotaría en la reformulación de los principios político-criminales sino que se proyectaría asimismo sobre el ámbito de la dogmática y de la técnica legislativa.

La anterior afirmación requiere quizás todavía de una última precisión. Toda aproximación teórica al conjunto de normas que conforman la legislación vigente de un momento histórico dado (en nuestro caso, el ordenamiento penal de nuestro entorno jurídicocultural), no puede desconocer, ni aún menos ignorar, la extrema complejidad que caracteriza todo proceso normativo. De ahí que cuando se habla del Derecho penal del miedo, ni mucho menos quiere significarse con ello la existencia de una legislación penal que responda en todas sus manifestaciones a las características y presupuestos descritos como propios de aquél. Y ello no sólo por las razones ya aludidas de circunscripción a determinados ámbitos de criminalidad o problemas sociales (con lo que la situación de convivencia con los sectores más "clásicos" del Derecho penal es incuestionable) sino, ante todo, porque como ya afirmara Quintero Olivares en su día, si bien refiriéndose a la significación política del Derecho penal, "los códigos penales ofrecen con frecuencia un conglomerado de preceptos que no responden a una ideología única, sino que son producto de aluvión de las diversas corrientes de ideología que han intervenido en su creación o gestación histórica". ${ }^{70}$ Todo ello me lleva a insistir, en relación con el tema que me ocupa ahora mismo, en que la funcionalización ilegítima del Derecho penal en el Derecho penal del miedo no es tanto un problema "cuantitativo" como "cualitativo".

En cuanto a la segunda de las cuestiones, -esto es, la relación entre instrumentalización política y funcionalización ilegítima-, de todo lo expuesto podría derivarse la imposibilidad de concebir dicha relación como de causa-efecto en ninguno de los dos sentidos: ni puede decirse que toda instrumentalización política tenga como consecuencia una funcionalización ilegítima del Derecho penal ni que toda funcionalización ilegítima del Derecho penal derive necesariamente de la instrumentalización política. En el primer caso, porque como ha sido señalado, pueden darse supuestos puntuales de instrumentalización política que por más que deban denunciarse por su carácter tendencialmente peligroso así como instarse en la medida de lo posible su erradicación del conjunto normativo, no alteran en términos generales la legítima función de protección de bienes jurídicos. En el segundo

\footnotetext{
${ }^{70}$ QUINTERO OLIVARES, G., Represión penal y Estado de Derecho, Barcelona: Dirosa, 1976, p. 40.
} 
caso, porque existen formas de funcionalización del Derecho penal que lejos de ser producto de una determinada actitud política frente al Derecho penal (origen del fenómeno de la instrumentalización), son fruto de construcciones doctrinales y, por ello, únicamente calificables de "ilegítimas" desde posturas contrarias y con todas las precauciones necesarias desde el momento en que nos ubicamos en el ámbito de lo opinable. Por lo demás, la tenue frontera que puede establecerse en ocasiones entre los dos fenómenos se pone de manifiesto cuando la orientación a fines políticos, extremo que caracteriza el concepto de instrumentalización política, es considerada, en sí misma, una forma de funcionalización ilegítima en tanto que "reorientación" de la misión del Derecho penal.

Llevada esta última observación al ámbito del Derecho penal del miedo, cabría preguntarse si en vez de la seguridad subjetiva, no es la orientación a fines políticos la verdadera función encubierta del Derecho penal. En mi opinión, son dos fenómenos que si bien terminan prácticamente por superponerse en el plano de la realidad, encuentran sus particulares razones en el origen del planteamiento: en una sociedad del riesgo, el legislador percibe en primer lugar la seguridad subjetiva como necesidad social y, a sabiendas del efecto que produce en la colectividad su satisfacción y las consecuencias que para sus propios intereses políticos se derivan de ello, procede a buscar el instrumento que le resulte menos "costoso" e idóneo a este fin: el Derecho penal. La entrada que ello supone en el círculo vicioso al que aludía más arriba como causa de la intensificación de la intervención penal, será la medida de la relación entre ambos conceptos en el Derecho penal del miedo.

\section{La orientación a la seguridad subjetiva como manifestación del Derecho penal simbólico}

Señalaba, a propósito de la instrumentalización política del Derecho penal, que una intervención impulsada por la voluntad de producir una sensación colectiva de resolución de los problemas responde más a criterios de urgencia y de interés político que a criterios de eficacia material. Con la expresión Derecho penal simbólico se describe la ineficacia instrumental que pueden acusar las normas penales promulgadas con estos fines esencialmente sociopolíticos: cuando el objetivo manifiesto y el objetivo latente de la intervención penal no coinciden -lo que se da en el supuesto de funcionalización ilegítima encubierta que afecta al Derecho penal del miedo- derivándose de ello la ineficacia instrumental de la norma penal en cuestión, puede hablarse de efectos meramente simbólicos.

Sin embargo, conviene hacer una puntualización: la calificación de simbólico del Derecho penal del miedo se realiza desde la postulación de la protección de bienes jurídicos como único y legítimo fin del Derecho penal, se realiza por tanto desde posturas críticas con el Derecho penal del miedo y sólo desde esta perspectiva es otro de sus rasgos. Para quien crea firmemente en la conveniencia de la reorientación de la misión del Derecho penal, el bien jurídico puede dejar de ser criterio nuclear de valoración $\mathrm{y}$, en consecuencia, los posibles juicios de eficacia se realizarán desde presupuestos distintos. La consideración del Derecho penal simbólico como característica del Derecho penal del miedo remite, por tanto, una vez más, a una determinada opción doctrinal. 
MARQUÈS I BANQUÉ, Maria. "Problemas de legitimación del Derecho penal del miedo".

En efecto, cuando de Derecho penal simbólico se habla, no es extraño que sea en sentido crítico (hasta el punto de merecer duros calificativos como el de constituir "la banalización de la libertad" ${ }^{\prime 1}$ ), y básicamente para denunciar la falta de efectividad material de determinadas previsiones legales. No obstante, si bien es ésta la perspectiva del concepto que me interesa desarrollar en tanto que describe uno de los rasgos del Derecho penal del miedo, no es menos cierto que responde tan sólo a una de sus posibles lecturas. Así, mientras para unos la consideración como simbólica de una concreta medida legislativa indica simplemente su falta de eficacia real o instrumental, otros, desde posturas cercanas a la afirmación de funciones promocionales e integradoras de la pena, interpretan el efecto simbólico del Derecho penal en el sentido de señalización de la dirección a tomar por el sujeto, lo que a largo plazo para esta corriente doctrinal posibilita un correcto desarrollo social y permite afirmar una eficacia instrumental de distintas raíces (protección indirecta de los bienes jurídicos a partir de la función educadora de la norma penal, o, dando un paso más en el alejamiento cuando no abandono del criterio del bien jurídico, protección del sistema social vigente a través de la confirmación del Derecho y del "ejercicio" en la fidelidad al mismo $)^{72}$. Situándose en esta última perspectiva, Manuel Cancio Meliá ha considerado, por ejemplo, que es precisamente la combinación entre el Derecho penal simbólico (la tipificación penal como mecanismo de creación de identidad social) y el punitivismo (la idea del incremento de la pena como único instrumento de control de la criminalidad), la que explica el origen del Derecho penal del enemigo ${ }^{73}$.

Por otra parte, hay que decir que la legislación simbólica tiene distintas manifestaciones normativas -cuyo rasgo común es según criterio mayoritario la contraposición entre lo real

\footnotetext{
${ }^{71}$ CARBONELL MATEU, "Reflexiones", cit. nota n ${ }^{\circ} 35$, p. 139.

72 Aspecto que ha sido descrito también como función ético-social del Derecho penal (en este sentido críticamente SILVA SÁNCHEZ, Aproximación, cit. nota n ${ }^{\circ}$ 49, pp. 300 y ss). Para un análisis de cada una de las corrientes apuntadas, véase, entre otros, a WELZEL y a JAKOBS respectivamente, como dos de sus máximos exponentes, si bien en relación con el primero cabe precisar que no es la expresión "función educadora" la empleada sino la de "función ético-social" calificándola incluso como de "misión profunda" del Derecho penal. Así, en opinión de WELZEL (Derecho penal alemán: Parte General, 11a. ed., 2a. ed. castellana, trad. de J. Bustos Ramírez y Sergio Yáñez Pérez, Santiago de Chile: Editorial Jurídica de Chile, 1976) "misión del Derecho penal es la protección de los bienes jurídicos mediante la protección de los elementales valores de acción ético-sociales" (p. 16), de manera que "al castigar el Derecho la efectiva inobservancia de los valores de la conciencia jurídica; protege al mismo tiempo los bienes jurídicos a los que están referidos aquellos valores de acto" (p. 13).

Ejemplo de las distintas corrientes que alimentan este debate es así mismo DÍEZ RIPOLLÉS ("El derecho penal simbólico", cit. nota n $^{\circ} 32$, pp. 5 y ss.), quien en aras a evitar los prejuicios que en su opinión se derivan de la desacreditación apresurada de los efectos simbólicos, propone sustituir amparándose en las ciencias sociales la expresión "efectos instrumentales" por la de "efectos materiales" (privándoles así del monopolio de la utilidad) y la de "efectos simbólicos" por la de "efectos expresivo-integradores"(expresivos cuando se suscitan emociones o sentimientos en las conciencias e integradores cuando se generan determinadas representaciones valorativas en las mentes), considerando a estos últimos "uno de los pilares fundamentales de la utilización legítima de la pena" (p. 5) y a unos y otros "en determinadas circunstancias medios adecuados para la prevención de comportamientos lesivos o peligrosos para los bienes jurídicos y, en tal medida, instrumentales para tal objetivo" (p. 6).

${ }^{73}$ CANCIO MELIÁ, M., “¿'Derecho Penal’ del enemigo?”, en: JAKOBS, G., CANCIO MELIÁ, M., Derecho penal del enemigo, Madrid: Civitas, 2003, pp. 57-102.
} 
y lo aparente ${ }^{74}$ - ocupándome aquí tan sólo de una de ellas y centrándola además al campo del Derecho penal ${ }^{75}$.

Desde la opción doctrinal que comparto, el recurso al Derecho penal se justifica únicamente en tanto que idóneo para la protección de bienes jurídicos debiéndose medir la idoneidad por criterios de instrumentalidad, de eficacia. El juicio de eficacia de una norma penal se efectuará desde el bien jurídico protegido, pudiéndose afirmar como instrumental en la medida en que la norma penal tenga capacidad para incidir de forma positiva sobre el bien jurídico en el plano de la realidad ${ }^{76}$. La adopción de medidas legislativas meramente simbólicas supone, por el contrario, atender, bajo una falsa apariencia de orientación al bien jurídico y, por tanto, de instrumentalidad, a otros objetivos de carácter latente. Por "objetivos de carácter latente" cabrá entender, por su parte, todas aquellas funciones que puede cumplir el Derecho penal y que pueden abarcar "desde la satisfacción de una 'necesidad de actuar' a un apaciguamiento de la población, hasta la demostración de un Estado fuerte"77. La prevalencia de las funciones latentes por encima de la protección de bienes jurídicos en la promulgación de una norma penal, con la inobservancia de los principios informadores de la intervención que ello puede suponer, se erige, por tanto, como una de las posibles causas de su ineficacia instrumental y, en la medida en que así sea, podrá afirmarse que dicha norma tiene únicamente efectos simbólicos ${ }^{78}$.

La estrecha relación que puede establecerse entre los fenómenos de instrumentalización política, funcionalización ilegítima y Derecho penal simbólico, se pone de manifiesto a partir del concepto de función latente. Por una parte, es suficiente con remitirse a las

\footnotetext{
${ }^{74}$ No así DÍEZ RIPOLLÉS ("El derecho penal simbólico", cit. nota no 32, p. 15), para quien "el fenómeno del Derecho penal simbólico no se puede entender como un problema de desajuste entre los efectos que se pretenden (fin) o se creen (función) conseguir, y los que realmente se pretenden u obtienen", sino que "es más adecuado verlo como un problema de deslegitimación de la intervención penal por carecer de tal legitimidad una buena parte de los efectos producidos, o los más significativos de entre ellos" (sin admitir este autor, recordemos, la previa descalificación, total o parcial, de los efectos expresivo-integradores).

75 El carácter ambivalente del concepto de Derecho penal simbólico era señalado por PRITTWITZ, "Funktionalisierung ", cit. nota $\mathrm{n}^{\circ}$ 17, p. 439 y por SEELMANN, "Risikostrafrecht", cit. nota no 17, pp. 461 y ss. Por otra parte, las distintas formas de legislación simbólica son reseñadas en el ámbito del Derecho penal por HASSEMER, "Derecho penal simbólico", cit. nota n² 26, pp. 19 y ss., y con carácter general por NOLL, P., "Symbolische Gesetzgebung", Zeitschrift für schweizerisches Recht 1981, 1.Halbband, pp. 356 y ss., así como más extensamente por VOß, M., Symbolische Gesetzgebung. Fragen zur Rationalität von Strafgesetzgebungsakten, Ebelsbach: Verlag Rolf Gremer, 1989.

${ }^{76}$ Afirmación que entiendo debe quedar al margen del debate doctrinal suscitado en el seno de las teorías de la pena en torno a la indemostrabilidad del efecto preventivo como pretendida medida de la ineficacia del Derecho penal. Aquí se quiere únicamente significar que objetivo real de la intervención penal es la protección del bien jurídico, que es, por tanto, su efectiva conservación y no otros fines más o menos encubiertos lo que configura la voluntad del legislador y que, en consecuencia, éste habrá atendido a los criterios de intervención que posibilitan una adecuada y efectiva protección del bien jurídico. En este sentido, uno de los indicadores de ineficacia de una determinada norma penal será su déficit de aplicación a pesar de la constatación de las llamadas "cifra negra" o "cifra gris".

${ }^{77}$ HASSEMER, "Derecho penal simbólico", cit. nota n' 26, p. 24.

${ }^{78}$ En este mismo sentido, CANCIO MELIÁ, “¿'Derecho Penal”” del enemigo?”, cit. nota no 73, p. 8 (versión electrónica). La ineficacia instrumental de una norma penal puede darse por otras causas además de por su carácter simbólico. En este sentido, por ejemplo, SEELMANN, "Risikostrafrecht", cit. nota no 17, pp. 456 y 457, indica los problemas de imputación en las conductas de carácter serial como una de ellas.
} 
MARQUÈS I BANQUÉ, Maria. "Problemas de legitimación del Derecho penal del miedo".

explicaciones efectuadas con relación a las particularidades de estos fenómenos en una sociedad del riesgo: se trata más bien de aplacar miedos y cumplir con las expectativas sociales de actuación estatal que de actuar sobre el bien jurídico a pesar de que así pueda afirmarse. En el seno del Derecho penal del miedo se da prioridad a una función latente, cual es la satisfacción de necesidades de psicología social, en detrimento de la efectiva protección de bienes jurídicos, extremo que caracteriza la definición de legislación simbólica. Es por ello que asentadas las características de instrumentalización política y funcionalización ilegítima como consecuencias de la orientación a la seguridad subjetiva, la naturaleza simbólica del Derecho penal del miedo puede ya derivarse como otra de sus características.

Por otra parte, el Derecho penal simbólico puede llegar a ser considerado en sí mismo una forma de funcionalización ilegítima. El efecto simbólico del Derecho penal ha sido señalado como otra de sus funciones a nivel descriptivo: se ha observado que la promulgación de una norma penal produce la convicción de la población acerca de la resolución de los problemas sociales, independientemente de que así sea ${ }^{79}$. La referencia a la "función simbólica" de las normas penales no sólo permite sino que aconseja insistir en la diferencia existente entre este concepto y el de "efecto simbólico" del Derecho penal. Así, mientras el "efecto simbólico" se refiere a la falta de instrumentalidad (lo que debe ponerse en relación con la tutela de los bienes jurídicos), por función simbólica debe entenderse, en cambio, el efecto de apariencia de instrumentalidad para la colectividad, independientemente de que ésta se dé o no en el plano de la realidad, con lo que nos situamos en el ámbito de las percepciones sociales y, con ello, pues mucho tienen que ver con lo subjetivo, de las funciones latentes del Derecho penal. Cabe añadir además, que éste no es el único significado atribuido al concepto de función simbólica, puesto que puede asignarse a esta expresión el mismo contenido que otros autores reservan a los conceptos de función educadora, promocional o ético-social del Derecho penal, sin que puedan observarse grandes diferencias entre ellos. Puede añadirse, incluso, que esta comprensión de la función simbólica del Derecho penal, basada en la equiparación entre "símbolo" y "mensaje penal", constituye uno de los contenidos "clásicos" de la expresión, sin perjuicio de que no todos los autores a los que puede remitirse el significado la utilizaran con carácter expreso en su día ${ }^{80}$.

\footnotetext{
${ }^{79}$ En este sentido SILVA SÁNCHEZ, Aproximación, cit. nota n ${ }^{\circ}$ 49, pp. 304 y ss..

${ }^{80}$ En este sentido, véase por ejemplo BARATTA, ("Funciones instrumentales", cit. nota no 21, p. 52), quien encuentra ya este significado de la función simbólica en la teoría sociológica de la pena de DURKHEIM; o HASSEMER ("Derecho penal simbólico", cit. nota n 26, p. 22), quien por su parte retrocede a MAURACH o WELZEL para quienes la pena, más allá de su carácter retributivo, ya tenía la función de "transmitir al condenado un sentimiento de responsabilidad, proteger la conciencia moral colectiva y asentar el juicio social ético". Efectivamente, véase, en relación con MAURACH, cómo entre los efectos de la pena retributiva describe los de naturaleza "social-psicológicos", cuyo significado es la de "verificación del Derecho para la generalidad" (además de la de expiación de la pena para el autor), concordando dicha verificación con las exigencias de la intimidación, entre las que se cuenta "el robustecimiento del ciudadano honrado en sus propósitos" (MAURACH, R., Tratado de Derecho Penal (trad. y notas de J. Córdoba Roda), Barcelona: Ediciones Ariel, 1962, pp. 65 y 80). En relación con WELZEL, cit. nota $\mathrm{n}^{\circ}$ 72. Véase también DÍEZ RIPOLLÉS, "El derecho penal simbólico", cit. nota n 32, p. 4, con abundante referencia bibliográfica sobre este significado en nota al pie de página núm. 7.

Otra forma de diferenciar los anteriores significados en LUZÓN PEÑA, D-M., "Función simbólica del Derecho penal y delitos relativos a la manipulación genética", en: ROMEO CASABONA, C.M. (Ed.),
} 
Nótese que motivo de crítica cuando se habla de Derecho penal simbólico es la prioridad que se da a las funciones latentes, no la existencia de las mismas ${ }^{81}$. Indicaba más arriba que la existencia de funciones latentes no merece en sí misma una valoración negativa, pues en ocasiones describen "efectos secundarios" del Derecho penal que pueden resultar incluso beneficiosos para la población. Pero apuntaba también que en ningún caso dichas funciones podían erigirse en criterio de legitimación de la intervención penal. Se ha señalado asimismo que la instrumentalización política del Derecho penal supone el abuso del recurso al instrumento punitivo como consecuencia de la conciencia por parte del legislador de la función simbólica que cumple el Derecho penal y de la "ganancia política" (Hassemer) que ello le representa ${ }^{82}$. En la medida en que la intensificación de la intervención penal se deba a ello y, por tanto, en la medida en que se instrumentalice políticamente el Derecho penal, se estará dando prioridad a una función latente, la simbólica, que en una sociedad del riesgo correrá paralela a la consecución de la seguridad subjetiva como necesidad de psicología social. Cuando ello llega a caracterizar el conjunto de la intervención penal, como es el caso del Derecho penal del miedo, puede afirmarse una funcionalización ilegítima del Derecho penal.

En este sentido cabe interpretar la afirmación de Hassemer según la cual el Derecho penal simbólico "aparece como una crisis del Derecho penal orientado a las consecuencias" Según este autor, "orientación a las consecuencias no significa automática supeditación (Selbstauflösung) a intereses político-criminales, de política de seguridad o de política interna, no supone la ciega adaptación a las tendencias de modernización y 'efectivización'. Orientación a las consecuencias significaba y significa todavía, la incorporación de los efectos prácticos del Derecho penal entre los argumentos de análisis y crítica de la ciencia penal" ${ }^{\prime 4}$. El concepto, por tanto, no definía en sí mismo un fenómeno negativo. De ahí que este autor se refiera con frecuencia a la "crisis de la orientación a las consecuencias": cuando la valoración de dichos efectos prácticos (entre ellos también las funciones latentes

Genética y Derecho Penal, Bilbao: Cátedra de Derecho y Genoma Humano, Granada: Comares, 2001, pp. 4952.

${ }^{81}$ Incluso, claro está, en relación con la llamada "función ético-social", la cual, en el sentido también descrito de "aptitud para producir un cierto número de representaciones individuales o colectivas, valorizantes o desvalorizantes", ha sido considerada como "inescindible de la (función) instrumental, a la que sirve de complemento" (TERRADILLOS BASOCO, "Función simbólica", cit. nota n ${ }^{\circ}$ 30, p. 10; en el mismo sentido DÍEZ RIPOLLÉS, "El derecho penal simbólico", cit. nota $\mathrm{n}^{\circ}$ 32, p. 3; y MUÑOZ LORENTE, J., "Obligaciones constitucionales de incriminación y Derecho penal simbólico", Revista de Derecho y Proceso Penal Año 2001-2, núm. 6, p. 118). Las reticencias que despierta dicha función en ciertos sectores doctrinales, se deben, no a su identificación o reconocimiento entre las funciones latentes, sino a las consecuencias a las que ha contribuido la sublimación de la misma en la evolución actual del pensamiento penal.

${ }^{82}$ HASSEMER, W., "El destino de los derechos del ciudadano en un Derecho penal 'eficaz"” (trad. de F. Muñoz Conde), Estudios Penales y Criminológicos XV (Santiago de Compostela, 1992), p. 190.

${ }^{83}$ HASSEMER, "Derecho penal simbólico", cit. nota no 26, p. 25.

${ }^{84}$ HASSEMER, "Perspektiven", cit. nota $\mathrm{n}^{\circ}$ 22, p. 485. Véase la definición de este autor de la idea de orientación a las consecuencias en Fundamentos del Derecho penal, (trad. de F. Muñoz Conde y L. Arroyo Zapatero), Barcelona: Bosch, 1984, p. 34 y ss. Más recientemente, y a propósito del tema aquí abordado, se refiere a la orientación a las consecuencias en HASSEMER, W., "Libertá e sicurezza alla luce della politica criminale“, en: DONINI, M.; PAVARINI, M. (Eds.), Sicurezza e Diritto Penale, Bologna: Bononia University Press, 2011, p. 61. En España, recoge expresamente la concepción de HASSEMER; MUÑOZ CONDE, F., "Presente y futuro de la Dogmática jurídico-penal”, Revista Penal núm. 5 (2000), p. 46. 
MARQUÈS I BANQUÉ, Maria. "Problemas de legitimación del Derecho penal del miedo".

del Derecho penal) pasan a primer término de consideración por parte del legislador, cabe hablar de funcionalización e instrumentalización del Derecho penal como fenómeno negativo. En opinión de este autor, por consiguiente, lo que cabe criticar es la experiencia legislativa en torno a la orientación a las consecuencias.

A modo de conclusión de este apartado: por Derecho penal simbólico se entenderá, por tanto, la falta de eficacia instrumental de las normas penales derivada de la prioridad de funciones latentes, las cuales en una sociedad del riesgo serán principalmente la función simbólica y la función de satisfacción de necesidades de psicología social. El recurso a medidas legislativas meramente simbólicas como rasgo típico del tratamiento normativo de los procesos de riesgo surgidos con el progreso técnico fue, por lo demás, confirmado por la doctrina en múltiples ocasiones. ${ }^{85}$

De nuevo estamos ante un fenómeno que admite manifestaciones meramente puntuales (y no por ello menos criticables desde el punto de vista del bien jurídico), o que puede predicarse en términos generales del conjunto de normas que conforman el sistema penal vigente, apareciendo entonces como síntoma de una profunda transformación de los presupuestos del Derecho penal, como es el caso del Derecho penal del miedo.

\section{Conclusiones}

En las sociedades occidentales actuales está creciendo de manera visible el número de leyes penales que sólo se explican desde el deseo de calmar los sentimientos de inseguridad que sufren los ciudadanos. Esto se explica, entre otras razones, por la progresiva colectivización del miedo, hasta el punto de ser cada vez más habituales expresiones como la de "sociedad del miedo" para definir la época en que vivimos. A día de hoy ésta es una idea difícilmente refutable a la vista de los ya numerosos estudios dedicados a este fenómeno tanto desde la perspectiva del Derecho penal, como de la Criminología, la Victimología y la Sociología.

Esa idea de la seguridad como meta prioritaria a alcanzar a cualquier precio por el Derecho penal tiene una génesis en la que han intervenido, y así se reconoce, diferentes factores, que se han ido cristalizando a su vez en transformaciones del Derecho penal. Así, si del progreso técnico y la revolución tecnológica surgió el uso y abuso de las formas de anticipación de la tutela penal y muy particularmente de las estructuras típicas de peligro (Derecho penal del riesgo), más tarde con la evolución del tratamiento político y social de los problemas de delincuencia en las ciudades se ha reabierto camino la idea de la inocuización (Derecho penal de la seguridad ciudadana). No puede olvidarse en este elenco de factores la dimensión internacional y la repercusión mediática de determinados hechos criminales violentos de indiscutible relevancia como los vinculados al terrorismo, para cuya lucha se entiende automáticamente legitimada cualquier clase de excepciones a los principios penales básicos. El Derecho penal actual ha derivado también en un Derecho

\footnotetext{
${ }^{85}$ Además de los autores ya citados en este apartado: ARROYO ZAPATERO, "Derecho y riesgo", cit. nota no 16, p. 61 y PALAZZO, F., "I confini della tutela penale: selezione dei beni e criteri de criminalizzazione", Rivista Italiana di Diritto e Procedura Penale 2 (1992), p. 458. En relación con el Derecho penal económico y del medio ambiente, ALBRECHT, "Das Strafrecht”, cit. nota n 27, p. 41.
} 
penal de la exclusión generando subsistemas penales dedicados a los "no ciudadanos" o "enemigos", que son apartados de la sociedad a través de implacables medidas punitivas y de políticas de segregación social en una imparable carrera de violencia institucional. Este proceso, consolidado en EE.UU. y en constante progreso en otros países, cuenta ya con manifestaciones legislativas en España.

El comportamiento legislativo indicado, que ya ha dado muestras perceptibles de su fuerza y que puede ir en aumento, ha de ser enjuiciado y valorado a la luz de las ideas esenciales relativas a la legitimidad del Derecho penal y del recurso a la represión en un Estado social y democrático de Derecho. Que la actividad legisladora se explique por los objetivos apuntados no puede dar paso a la inaceptable idea de que la finalidad perseguida por la norma -esto es, por el legislador que la crea- es a la vez su propia justificación. La explicación funcional que se ofrece de una decisión no confiere sin más justificación profunda, esto es, legitimación constitucional y material, a la norma que emana de ella.

Indudablemente el problema de la legitimación no es privativo de las leyes penales sino que pertenece a la problemática común de toda la Teoría del Derecho. Ahora bien, enfrentados a un fenómeno perceptible no solo en la praxis legislativa penal sustantiva, sino también en el orden procesal, en la legislación penitenciaria y en el uso de la potestad sancionadora de la Administración, es obligado abordar la crítica con la voluntad de evitar confundir lo que "es" con lo que "debería ser". La cada vez más desbordada sensación de inseguridad por parte de la ciudadanía explica sin duda determinadas políticas penales, pero no las justifica o legitima. Partir de esa creencia entraña por lo demás otro riesgo: el de ensalzar la política legislativa penal de un determinado momento hasta el punto de confundirla con lo que es o debería ser verdaderamente la Política Criminal, y en consecuencia, distorsionar una de las tareas básicas encomendadas al penalista.

Consecuencia gravísima para los principios esenciales del Derecho penal, construidos tras décadas de esfuerzos políticos y jurídicos, es un hecho también visible: el abandono del principio de exclusiva protección de bienes jurídicos en favor de la meta de ofrecer al ciudadano una "seguridad subjetiva". Ello tiene consecuencias transcendentales, ante todo, para la legitimación del Derecho penal, pero también las puede tener en la interpretación y aplicación del sistema legal penal, procesal y penitenciario.

Un "Derecho penal del miedo" así caracterizado tiene como finalidad, ya no únicamente prevenir conductas objetivamente peligrosas o lesivas para los bienes jurídicos, sino gestionar y controlar los miedos de la ciudadanía, y, por si no bastara con esa desviación de su función, independientemente del grado de racionalidad de los mismos. Lo que en un tiempo se tuvo como función latente, indirecta o refleja de la aplicación de la represión penal, pasa a ser función primordial del Derecho penal, en detrimento de la tarea de contribuir a crear un marco de convivencia presidido por la idea de aplicar en lo posible la menor cantidad de represión al menor número de personas. Si se estimara que la seguridad subjetiva exige exasperación de los castigos o Derecho penal máximo, esa sería la vía lógica que impondría la "ideología de la seguridad". 
MARQUÈS I BANQUÉ, Maria. "Problemas de legitimación del Derecho penal del miedo".

Un amplio sector de la doctrina penal venía advirtiendo de los problemas que se avecinaban desde hace considerable tiempo, sin que los Gobiernos hayan prestado especial atención a sus críticas y peticiones. En los años ochenta y sobre todo noventa del siglo XX, unos desarrollaban el concepto de Derecho penal del riesgo entendiendo como tal el conjunto de respuestas dogmáticas a la inevitable adaptación del Derecho penal a las nuevas formas criminales de la sociedad del riesgo (anticipación de la intervención penal, bienes jurídicos colectivos, problemas de causalidad e imputación objetiva, autoría y participación, reformulación de la culpabilidad...). Por aquel entonces muchos eran los que advertían de las consecuencias político-criminales que todas esas tendencias doctrinales y legislativas entrañaban (funcionalización ilegítima e instrumentalización política del Derecho penal, administrativización, desformalización, recurso al Derecho penal simbólico...), haciendo un llamamiento a la contención. Sin embargo, tales llamadas a la prudencia y a preservar las más importantes conquistas penales fueron siendo arrinconadas.

Quizás, reivindicar el rol de los principios clásicos garantistas del Derecho penal liberal en la actualidad, puede ser tildado poco menos que de "ingenuidad iluminística" ${ }^{86}$. Sin embargo, justamente en un contexto como el actual entiendo que cobra sentido volver al discurso de la legitimación del Derecho penal y revisitar el marco conceptual que debería servir de base en la evaluación crítica de las políticas legislativas penales de un Estado social y democrático de Derecho. En la medida que tales políticas puedan considerarse expresión del "Derecho penal del miedo", puede afirmarse que adolecerán de los problemas de legitimación aquí analizados.

\footnotetext{
${ }^{86}$ Así se autocalifica PULITANÒ, D., "Sicurezza e Diritto Penale", en: DONINI, M.; PAVARINI, M. (Eds.), Sicurezza e Diritto Penale, Bologna: Bononia University Press, 2011, p. 127.
} 
Polít. crim. Vol. 12, No 24 (Diciembre 2017), Art. 2, pp. 690-730.

[http://www.politicacriminal.cl/Vol_12/n_24/Vol12N24A2.pdf]

\section{REFERENCIAS BIBLIOGRÁFICAS}

ALBRECHT, Peter-Alexis, "Das Strafrecht auf dem Weg vom liberalen Rechtsstaat zum sozialen Interventionsstaat - Entwicklungstendenzen des materiellen Strafrechts", 12.Strafverteidigertag, 1989, pp. 30-63 (también en: Kritischen Vierteljahresschrift für Gesetzgebung und Rechtswissenschaft, 1988, pp. 182-209).

ALCÁCER GUIRAO, Rafael, "Los fines del Derecho penal. Una aproximación desde la filosofía política", Anuario de Derecho Penal y Ciencias Penales 1998, pp. 365-587. , "Prevención y garantías: conflicto y síntesis", DOXA.Cuadernos de Filosofía del Derecho núm. 25 (2002), pp. 139-175.

ARROYO ZAPATERO, Luis, "Derecho y riesgo", Iniuria (Revista de Responsabilidad Civil y Seguro), núm. 8, octubre-diciembre 1995, Centro de Estudios del Seguro, pp. 57-68.

ARZT, Gunther, "Probleme der Kriminalisierung und Entkriminalisierung sozialschädlichen Verhaltens", Kriminalistik 1981, pp. 117-122.

BARATA, Francesc, "Las nuevas fábricas del miedo. Los mass media y la inseguridad ciudadana", en: MUÑAGORRI LAGUÍA, I. (Coord.), La protección de la seguridad ciudadana, Oñati : The Oñati International Institute for the Sociology of Law, 1995, pp. 83-94.

BARATTA, Alessandro, "Funciones instrumentales y simbólicas del Derecho penal: una discusión en la perspectiva de la Criminología crítica", Pena y Estado núm. 1, septiembre-diciembre 1991, pp. 37-55.

BARBERO SANTOS, Marino, Política y Derecho penal en España, Madrid: Tucar, 1977.

BAUCELLS LLADÓS, Joan, "Medios de comunicación y populismo punitivo. Revisión teórica del concepto y análisis de la reforma penal en materia de hurto“, Revista Penal núm. 27, 2011, pp. 111-131.

BECK, Ulrich, La sociedad del riesgo: hacia una nueva modernidad (trad. española de J. Navarro, D. Jiménez, M.R. Borrás), Barcelona: Paidós, 1998.

BELL, Emma, Criminal Justice and Neoliberalism, Londres: Palgrave Macmillan UK, 2011.

BOBBIO, Norberto, "Sobre el principio de legitimidad", en: RUIZ MIGUEL, A. (Ed.), Contribución a la teoría del Derecho, Valencia: Fernando Torres DL, 1980, pp. 307316.

BRANDARIZ GARCÍA, José Ángel., Política criminal de la exclusión, Granada: Comares, 2007.

"Nuevos riesgos, nuevas ansiedades y expectativas sociales en materia de seguridad ante el delito", en: FARALDO CABANA, P. (Dir.), Derecho penal de excepción. Terrorismo e inmigración, Valencia: Tirant lo Blanch, 2007, pp. 139-159.

BRICOLA, Franco, "Tecniche di tutela penale e tecniche alternative di tutela", en: DE ACUTIS, M.; PALOMBARINI, G. (Eds.), Funzioni e limiti del diritto penale. Alternative di tutela, Padova: CEDAM, 1984, pp. 3-84.

CANCIO MELIÁ, Manuel, “¿'Derecho Penal' del enemigo?”, en: JAKOBS, G., CANCIO MELIÁ, M., Derecho penal del enemigo, Madrid: Civitas, 2003, pp. 57-102.

"Dogmática y Política Criminal en una teoría funcional del delito", en: JAKOBS, G.; CANCIO MELIÁ, M., Conferencias sobre temas penales, Buenos Aires: Rubinzal-Culzoni Editores, 2004 (reimpresión), pp. 121-147. 
MARQUÈS I BANQUÉ, Maria. "Problemas de legitimación del Derecho penal del miedo".

CARBONELL MATEU, Joan Carles, Derecho penal: concepto y principios constitucionales, 3a. ed., Valencia: Tirant lo Blanch, 1999.

"Reflexiones sobre el abuso del Derecho penal y la banalización de la legalidad”, en: ARROYO ZAPATERO, L.A.; BERDUGO GÓMEZ DE LA TORRE, I. (Coords.), Homenaje al Dr. Marino Barbero Santos: 'in memoriam', Vol. 1, Cuenca: Ediciones de la Universidad de Castilla-La Mancha; Salamanca: Ediciones de la Universidad de Salamanca, 2001, pp. 129-144.

CARBONELL MATEU, Joan Carles; GUARDIOLA GARCÍA, Javier, "Consideraciones sobre la reforma penal de 2003", Revista Jurídica de la Comunidad Valenciana 2004 (12), pp. 9-63.

CASTAÑO TIERNO, Pablo, “¿Otra política penal es posible? Un estudio sobre la viabilidad de una política criminal alternativa al populismo punitivo", Estudios Penales y Criminológicos vol. XXXIV (2014), pp. 561-638.

CUERDA RIEZU, Antonio, El legislador y el Derecho penal (una orientación a los orígenes), Madrid: Editorial Centro de Estudios Ramon Areces, 1991.

"Los medios de comunicación y el Derecho penal", en: ARROYO ZAPATERO, L.A.; BERDUGO GÓMEZ DE LA TORRE, I. (Coords.), Homenaje al Dr. Marino Barbero Santos: 'in memoriam', Vol. 1, Cuenca: Ediciones de la Universidad de Castilla-La Mancha; Salamanca: Ediciones de la Universidad de Salamanca, 2001, pp. 187-207.

DE LA MATA BARRANCO, Norberto J., "Las reformas penales de 2003: consideraciones generales sobre la quiebra de algunos principios que deben definir toda intervención penal", en: FARALDO CABANA, P. (Dir.), Política Criminal y reformas penales, Valencia: Tirant lo Blanch, 2007, pp. 11-34.

DEL ROSAL BLASCO, Bernardo, "La estrategia actuarial de control del riesgo en la política criminal y en el Derecho Penal", en: CARBONELL MATEU, J.C.; GONZÁLEZ CUSSAC, J.L.; ORTS BERENGUER, E. (Dirs.), Constitución, Derechos Fundamentales y Sistema Penal, Tomo I, Valencia: Tirant lo Blanch, 2009, pp.473-497.

DEMETRIO CRESPO, Eduardo, 'El 'Derecho penal del enemigo' darf nicht sein! Sobre la ilegitimidad del llamado 'Derecho penal del enemigo' y la idea de seguridad", en: VV.AA., El Derecho penal frente a la inseguridad global, Albacete: Ediciones Bomarzo, 2007, pp. 123-148.

DENNINGER, Erhard, "Der Präventions-Staat”, Kritische Justiz núm. 21, 1988-1, pp. 115.

DÍEZ RIPOLLÉS, José Luis, "Exigencias sociales y política criminal”, Claves de Razón Práctica núm. 85 (1998), pp. 48-53.

, "El bien jurídico protegido en un derecho penal garantista", Nuevo Foro Penal núm. 60, enero-abril 1999, pp. 115-133.

,"El derecho penal simbólico y los efectos de la pena", Actualidad Penal núm. 1, semana del 1 al 7 de enero de 2001, pp. 1-22 (también en: ARROYO ZAPATERO, L.; NEUMANN, U.; NIETO MARTÍN, A. (Coords.), Crítica y Justificación del Derecho Penal en el cambio de siglo, Cuenca: Ediciones de la Universidad de Castilla-La Mancha, 2003, pp. 147-172).

, "De la sociedad del riesgo a la seguridad ciudadana: un debate desenfocado", en: Homenaje al profesor Dr. Gonzalo Rodríguez. Mourullo, Madrid: Civitas, 2005, pp. 267-305. 
Polít. crim. Vol. 12, No 24 (Diciembre 2017), Art. 2, pp. 690-730.

[http://www.politicacriminal.cl/Vol_12/n_24/Vol12N24A2.pdf]

, "La víctima del delito en la política criminal y el derecho penal", Jueces para la Democracia núm. 57 (2006), pp. 33-35.

DONINI, Massimo, "La relación entre Derecho penal y política: método democrático y método científico" (trad. de C. Méndez Rodríguez), en: ARROYO ZAPATERO, L.; NEUMANN, U.; NIETO MARTÍN, A. (Coords.), Crítica y Justificación del Derecho Penal en el cambio de siglo, Cuenca: Ediciones de la Universidad de Castilla-La Mancha, 2003, pp. 69-97.

"Sicurezza e Diritto Penale. La sicurezza come orizzonte totalizzante del discorso penale“, en: DONINI, M.; PAVARINI, M. (Eds.), Sicurezza e Diritto Penale, Bologna: Bononia University Press, 2011, pp. 11-32.

FARALDO CABANA, Patricia (Dir.), Política Criminal y reformas penales, Valencia: Tirant lo Blanch, 2007.

, Derecho penal de excepción. Terrorismo e inmigración, Valencia: Tirant lo Blanch, 2007

FERRAJOLI, Luigi, "El derecho penal mínimo" (trad. de R. Bergalli), Poder y Control núm. 0, 1986, pp.25-48.

1990.

Diritto e ragione. Teoria del garantismo penale, 2a. ed., Roma-Bari: Laterza,

, "El derecho como sistema de garantías" (trad. de P. Andrés Ibáñez), Nuevo Foro Penal núm. 60, enero-abril 1999, pp.59-75.

FUENTES OSORIO, Juan Luis, "Los medios de comunicación y el Derecho penal", Revista Electrónica de Ciencia Penal y Criminología 07-16 (2005).

GARCÍA ARÁN, Mercedes, "Delincuencia, inseguridad y pena en el discurso mediático", en: MUÑOZ CONDE F. (Dir.), Problemas actuales del Derecho Penal y la Criminología, Valencia: Tirant lo Blanch, 2008, pp. 85-113.

GARCÍA RIVAS, Nicolás, El poder punitivo en el Estado democrático, Cuenca: Universidad de Castilla-La Mancha, 1996.

GÓMEZ BENÍTEZ, Jose Manuel, "Sobre la teoría del 'bien jurídico' (aproximación al ilícito penal)", Revista de la Facultad de Derecho de la Universidad Complutense de Madrid 1983, pp. 85-111.

GÓMEZ MARTÍN, Víctor, "Libertad, seguridad y "sociedad del riesgo"”, en: GÓMEZ MARTín, V. (Coord.), La Política Criminal en Europa, Barcelona: Atelier, 2004, pp. 59-90.

GONZÁlEZ RUS, Juan José, Bien jurídico y Constitución (Bases para una teoría), Madrid: Fundación Juan March, 1983.

HASSEMER, Winfried, Fundamentos del Derecho penal (trad. y notas de F. Muñoz Conde y L. Arroyo Zapatero), Barcelona: Bosch, 1984.

, "Lineamientos de una teoría personal del bien jurídico" (trad. de Patricia S. Ziffer), Doctrina Penal año 12, n 45 a 48 (1989), pp. 275-285.

, "Derecho penal simbólico y protección de bienes jurídicos" (trad. de E. Larrauri), Nuevo Foro Penal núm. 51 (1991), pp. 17-30 (también Pena y Estado núm. 1, septiembre-diciembre 1991, pp. 23-36).

, "El destino de los derechos del ciudadano en un Derecho penal "eficaz"” (trad. de F. Muñoz Conde), Estudios Penales y Criminológicos XV (Santiago de Compostela, 1992), pp. 181-198. 
MARQUÈS I BANQUÉ, Maria. "Problemas de legitimación del Derecho penal del miedo".

, "Rasgos y crisis del Derecho penal moderno" (traducción de E. Larrauri), Anuario de Derecho Penal y Ciencias Penales Vol. 45, N 1 (1992), pp. 235-249.

"Perspectivas del Derecho penal futuro" (trad. de E. Anarte Borrallo), Revista Penal núm. 1 (1998), pp. 37-41.

"La medida de la Constitución", en: CARBONELL MATEU, J.C.; GONZÁLEZ CUSSAC, J.L.; ORTS BERENGUER, E. (Dirs.), Constitución, Derechos Fundamentales y Sistema Penal, Tomo I, Valencia: Tirant lo Blanch, 2009, pp. 975-992.

, "Libertá e sicurezza alla luce della politica criminale", en: DONINI, M.; PAVARINI, Massimo (Eds.), Sicurezza e Diritto Penale, Bologna: Bononia University Press, 2011, pp. 59-78.

HASSEMER, Winfried; MUNOOZ CONDE, Francisco, Introducción a la Criminología y al Derecho penal, Valencia: Tirant lo Blanch, 1989.

HERZOG, Felix, Gesellschaftliche Unsichercheit und strafrechtliche Daseinsvorsorge, Heidelberg: v. Decker, 1991.

"Límites al control penal de los riesgos sociales (Una perspectiva crítica ante el Derecho Penal de peligro)", Anuario de Derecho Penal y Ciencias Penales Vol. 46, $\mathrm{N}^{\circ} 1$ (1993), pp. 317-327.

HIRSCH, Joachim, Der Sicherheitsstaat. Das “Model Deutshcland," seine Krise und die neuen sozialen Bewegungen, Frankfurt am Main: Europäische Verlagsanstalt, 1980.

JIMÉNEZ DÍAZ, María José, "Sociedad del riesgo e intervención penal", Revista Electrónica de Ciencia Penal y Criminología 16-08 (2014), pp. 08:1-08:25.

JONGITUD ZAMORA, Jacqueline, "Legalidad, legitimidad y legitimación. Implicaciones éticas”, en: CÁCERES, E., Problemas contemporáneos de la Filosofía del Derecho, México: Universidad Nacional Autónoma de México, 2005, en: http://studylib.es/doc/4517646/18.-jongitud [última visita el 02.04.17].

KUHLEN, Lothar, "El Derecho penal del futuro" (trad. de A. Nieto Martín), en: ARROYO ZAPATERO, L.; NEUMANN, U.; NIETO MARTÍN, A. (Coords.), Crítica y Justificación del Derecho Penal en el cambio de siglo, Cuenca: Ediciones de la Universidad de Castilla-La Mancha, 2003, pp. 225-229.

LANDROVE DÍAZ, Gerardo, "El Derecho penal 'de la seguridad"”, La Ley, t.4 (2003), pp. 1923-1932 (ref. D- 224).

, "Una cierta política criminal", en: CARBONELL MATEU, JC; GONZÁLEZ CUSSAC, JL; ORTS BERENGUER, E. (Dir.), Constitución, Derechos Fundamentales y Sistema Penal, Tomo II, Valencia: Tirant lo Blanch, 2009, pp. 1079-1088.

LUHMANN, Niklas, Soziologie des Risikos, Berlin-New York: de Gruyter, 1991.

LUZÓN PEÑA, Diego-Manuel, "Función simbólica del Derecho penal y delitos relativos a la manipulación genética", en: ROMEO CASABONA, C. M. (Ed.), Genética y Derecho Penal, Bilbao: Cátedra de Derecho y Genoma Humano, Granada: Comares, 2001, pp. 49-59 (también en: VV.AA, Modernas tendencias en la ciencia del Derecho penal y en la Criminología, Madrid: Universidad Nacional de Educación a Distancia, 2001, pp. 131-139).

MAQUEDA ABREU, María Luisa, "Crítica a la reforma penal anunciada”, Jueces para la Democracia, núm. 47 (julio 2003), pp. 6-11.

MARINUCCI, Giorgio; DOLCINI, Emilio, Corso di Diritto Penale (Nozione, struttura e sistematica del reato), Milano: Giuffrè, 1995. 
MAURACH, Reinhart, Tratado de Derecho Penal (trad. y notas de J. Córdoba Roda), Barcelona: Ediciones Ariel, 1962, pp. 65 y 80.

MEDINA ARIZA, Juanjo, "Discursos políticos sobre seguridad ciudadana en la historia reciente de España”, en: PÉREZ ÁLVAREZ, F. (Ed.), Serta in Memoriam Alexandri Baratta, Salamanca: Universidad de Salamanca, 2004, pp. 1299-1320.

MENDOZA BUERGO, Blanca, El Derecho penal en la sociedad del riesgo, Madrid: Civitas, 2001.

MIR PUIG, Santiago, El Derecho Penal en el Estado Social y Democrático de Derecho, Barcelona: Ariel, 1994.

MORALES PRATS, Fermín, "Funciones del Derecho penal y sociedad civil", en: CANESTRARI, S. (Ed.), Il Diritto penale alla svolta di fine millenio (Atti del Convegno in ricordo di Franco Bricola, Bologna 18-20 maggio 1995), Torino: Giappichelli Editore, 1998.

MUÑOZ CONDE, Francisco, "Protección de los derechos fundamentales en el Código penal", en: VV.AA., Estudios sobre el Código penal de 1995 (Parte General), Madrid: CGPJ, 1996, pp. 437-456. También en Derecho y Cambio Social, Año 7, No22 (2011).

"Presente y futuro de la Dogmática jurídico-penal", Revista Penal núm. 5, enero 2000, pp. 44-51.

, "El nuevo Derecho penal autoritario", en: OCTAVIO DE TOLEDO Y UBIETO, E.; GURDIEL SIERRA, M.; CORTÉS BECHIARELLI, E. (Coords.), Estudios Penales en recuerdo del profesor Ruiz Antón, Valencia: Tirant lo Blanch, 2004, pp. 803-823.

MUÑOZ LORENTE, José, “Obligaciones constitucionales de incriminación y Derecho penal simbólico”, Revista de Derecho y Proceso Penal, Año 2001-2, núm. 6, pp. $103-$ 131.

MUSCO, Enzo, "A proposito del diritto penale "comunque ridotto"”, en: PEPINO, L. (Ed.), La riforma del diritto penale, Milano: Franco Angeli, 1993, pp. 170-183.

NAUCKE, Wolfgang, "Entwicklungen der allgemeinen Politik und der Zusammenhang dieser Politik mit der Reform der Strafrechts in der Bundesrepublik Deutschland", en: HASSEMER, W. (Ed.), Strafrechtspolitik, Frankfurt am Main: Peter Lang, 1987, pp.15-32.

, "La robusta tradizione del diritto penale della sicurezza: illustrazione con intento critico", en: DONINI, M.; PAVARINI, M. (Eds.), Sicurezza e Diritto Penale, Bologna: Bononia University Press, 2011, pp. 79-89.

NOLL, Peter, "Symbolische Gesetzgebung", Zeitschrift für schweizerisches Recht 1981, 1.Halbband, pp. 347-364.

PALAZZO, Francesco, "I confini della tutela penale: selezione dei beni e criteri de criminalizzazione", Rivista Italiana di Diritto e Procedura Penale 2/1992, pp. $453-$ 482.

PALIERO, Carlo Enrico, Minima non curat praetor, Padova: CEDAM, 1985.

PÉREZ CEPEDA, Ana Isabel, La seguridad como fundamento de la deriva del Derecho penal postmoderno, Madrid: Iustel, 2007.

PORTILLA CONTRERAS, Guillermo, El Derecho penal entre el cosmopolitismo universalista y el relativismo posmodernista, Valencia: Tirant lo Blanch, 2007. 
MARQUÈS I BANQUÉ, Maria. "Problemas de legitimación del Derecho penal del miedo".

PRITTWITZ, Cornelius, "Funktionalisierung des Strafrechts”, Strafverteidiger 9/1991, pp. 435-441.

"Strafrecht und Risiko", Frankfurt am Main: Vittorio Klostermann, 1993

"La concorrenza diseguale tra sicurezza e libertà", en: DONINI, M.; PAVARINI, M. (Eds.), Sicurezza e Diritto Penale, Bologna: Bononia University Press, 2011, pp. 105-118.

PULITANÒ, Domenico, "La teoria del bene giuridico fra codice e costituzione", La Questione Criminale 7/1981.

, "Sicurezza e Diritto Penale", en: DONINI, M.; PAVARINI, M. (Eds.), Sicurezza e Diritto Penale, Bologna: Bononia University Press, 2011, p. 127.

PUY, Ana, Percepción social de los riesgos, Madrid: Mapfre, 1995.

QUINTERO OLIVARES, Gonzalo, Represión penal y Estado de Derecho, Barcelona: Dirosa, 1976.

, La justicia penal en España, Pamplona: Aranzadi, 1998.

, Manual de Derecho penal, $3^{\mathrm{a}}$ Ed., Cizur Menor: Aranzadi, 2002.

, 'La politica criminale del 'centro-destra' spagnolo: le riforme penali dell'anno

2003”, Critica del Diritto N. 2-3-4, Aprile-Dicembre 2003, pp. 159-174.

, Adonde va el Derecho Penal. Reflexiones sobre las Leyes Penales y los

penalistas españoles, Madrid: Thomson Civitas, 2004.

, "La deriva y crisis de las ideas penales en España", en: OCTAVIO DE TOLEDO Y UBIETO, E.; GURDIEL SIERRA, M.; CORTÉS BECHIARELLI, E. (Coords.), Estudios penales en recuerdo del profesor Ruiz Antón, Valencia: Tirant lo Blanch, 2004, pp. 929-958.

QUINTERO OLIVARES, Gonzalo (Dir.), La reforma penal de 2010. Análisis y comentarios, Cizur Menor: Thomson Reuters Aranzadi, 2010.

, Comentario a la reforma penal de 2015, Cizur Menor: Thomson Reuters Aranzadi, 2015.

QUINTERO OLIVARES, Gonzalo; MUÑOZ CONDE, Francisco, La reforma penal de 1983, Barcelona: Ediciones Destino, 1983.

ROCHÉ, Sebastian, Le sentiment d'insécurité, Paris : Presses Universitaires de France, 1993.

ROXIN, Claus, "Sentido y límites de la pena estatal", en: ROXIN, C., Problemas básicos del Derecho penal (trad. de D.M. Luzón Peña), Madrid: Reus, 1976, pp. 11-36.

, "Franz von Liszt y la concepción políticocriminal del Proyecto Alternativo", en: ROXIN, C., Problemas básicos del Derecho penal (trad. de D.M. Luzón Peña), Madrid: Reus, 1976, pp. 37-70.

, "El desarrollo de la política criminal desde el Proyecto Alternativo" (trad. de J. Queralt), en: MIR PUIG, S. (Ed.), Política Criminal y Reforma del Derecho penal, Bogotá: Temis, 1982, pp. 5-27.

RUDOLPHI, Hans Joachim, "Los diferentes aspectos del concepto de bien jurídico" (trad. de E. Bacigalupo), Nuevo Pensamiento 1975, pp. 329-347.

SEELMANN, Kurt, "Risikostrafrecht: 'Die Risikogesellschaft' und ihre 'symbolische Gesetzgebung' im Umwelt -und Betäubungsmittelstrafrecht", Kritische Vierteljahresschrift für Gesetzgebung und Rechtswissenschaft 1992, pp. 452-471.

SILVA SÁNCHEZ, Jesús María, Aproximación al Derecho penal contemporáneo, Barcelona: J.M. Bosch Editor, 1992. 
Polít. crim. Vol. 12, No 24 (Diciembre 2017), Art. 2, pp. 690-730.

[http://www.politicacriminal.cl/Vol_12/n_24/Vol12N24A2.pdf]

, La expansión del Derecho penal. Aspectos de la política criminal en las sociedades postindustriales, Madrid: Civitas, 1999.

SIMON, Jonathan, Governing through Crime: How the War on Crime Transformed American Democracy and Created a Culture of Fear, Oxford-New York: Oxford University Press, 2007.

STORTONI, Luigi, "El riesgo procedente del desconocimiento tecnológico" (trad. de C. Méndez Rodríguez), Responsa Iurisperitorum Digesta, Vol. III, 2000, pp. 83-103.

TERRADILLOS BASOCO, Juan, "Función simbólica y objeto de protección del Derecho penal", Pena y Estado núm. 1, septiembre-diciembre 1991, pp. 9-22.

"Globalización, administrativización y expansión del Derecho penal económico”, en: TERRADILLOS BASOCO, J.; ACALE SÁNCHEZ, M. (Coords.), Temas de Derecho penal económico, Madrid: Trotta, 2004, pp. 219-240.

VIVES ANTÓN, Tomás Salvador, "Reforma política y Derecho Penal", en: VIVES ANTÓN, T.S., La libertad como pretexto, Valencia: Tirant lo Blanch, 1995, pp. 71133 (también en Cuadernos de Política Criminal núm. 3, 1977).

VOß, Monika, Symbolische Gesetzgebung. Fragen zur Rationalität von Strafgesetzgebungsakten, Ebelsbach: Verlag Rolf Gremer, 1989.

WELZEL, Hans, Derecho penal alemán: Parte General, 11a. ed., 2a. ed. castellana (trad. de J. Bustos Ramírez y S. Yáñez Pérez), Santiago de Chile: Editorial Jurídica de Chile, 1976. 